This PDF is a selection from a published volume from the National Bureau of Economic Research

Volume Title: NBER Macroeconomics Annual 2005, Volume 20

Volume Author/Editor: Mark Gertler and Kenneth Rogoff, editors

Volume Publisher: MIT Press

Volume ISBN: 0-262-07272-6

Volume URL: http://www.nber.org/books/gert06-1

Conference Date: April 8-9, 2005

Publication Date: April 2006

Title: A Bayesian Look at the New Open Economy Macroeconomics

Author: Thomas Lubik, Frank Schorfheide

URL: http://www.nber.org/chapters/c0071 


\section{A Bayesian Look at New Open Economy Macroeconomics}

Thomas Lubik, Johns Hopkins University

Frank Schorfheide, University of Pennsylvania and CEPR

\section{Introduction}

We develop a small-scale, two-country model and estimate it based on U.S. and Euro area data to study the magnitude of nominal rigidities; the transmission of monetary policy shocks, as well as demand and supply shocks; and the determinants of exchange rate fluctuations. The two economies are roughly of equal size and are each characterized by a unified monetary policy. While the trade linkages between the two currency areas are small compared to the linkages between, say, the United States and Canada, the U.S. dollar and the Euro are the two most important currencies to date. The conduct of monetary policy in these two currency areas is of interest to policymakers and academic researchers alike. Closed economy versions of our two-country model have been fitted to both U.S. and Euro area data and provide a natural benchmark for our empirical analysis.

An important feature of our model is that the real side, that is, preferences and technologies, is fully symmetric, while the nominal side allows for asymmetries. Specifically, we let nominal rigidities in domestic and import sectors differ across countries, and we distinguish between monetary policy rules at home and abroad. In the absence of trade in goods and financial assets, the model reduces to the standard New Keynesian dynamic stochastic general equilibrium (DSGE) model that has been widely used to study monetary policy in closed economies, for example, Woodford (2003). The main theoretical contribution is the extension of the small open economy framework in Monacelli (2005) to a large open economy setting. We introduce endogenous deviations from purchasing power parity (PPP) via price-setting importers that lead to imperfect pass-through. 
Structural empirical modeling is subject to the following tension: small, stylized models can lead to misspecification, whereas large-scale models with many exogenous shocks, for example, Smets and Wouters (2003), may introduce identification problems and computational difficulties. The Bayesian framework is rich enough to cope both with misspecification and identification problems. A section of this paper is devoted to these issues and provides an accessible introduction to the Bayesian estimation of DSGE models. We decided to work with a relatively small model that abstracts from capital accumulation. Nevertheless, due to the multicountry setting, we estimate roughly as many structural parameters as Smets and Wouters (2003) and fit the model to the same number of time series.

In our empirical analysis, we carefully document the sensitivity of posterior estimates to changes in model specification and prior distribution. We begin with a comparison of closed and open economy parameter estimates. If the long-run implications of the two-country model are taken seriously, and we impose common steady states for the United States and the Euro area, we find some discrepancies between open and closed economy estimates, in particular with respect to the price stickiness and the monetary policy reaction function of the Euro area. If the models are fitted to demeaned data, most of the discrepancies vanish. Estimation of the open economy model with diffuse priors alters the posterior distributions. Since we do not use direct observations on trade flows and import prices, the estimated price rigidities and import shares are very sensitive to the choice of prior.

An advantage of the Bayesian approach is that prior distributions can play an important role. Priors enable the researcher to include information that is available in addition to the estimation sample. This information helps to sharpen inference. Nondegenerate prior distributions can be used to incorporate inconclusive evidence. The resulting posteriors provide a coherent measure of parameter (and model) uncertainty that can inform academic debates and policymaking.

Unfortunately, the model has only limited success in explaining exchange rate movements. We introduce a nonstructural PPP shock that is designed to capture the deviations of the model from the data. The PPP shock generates most of the fluctuations in the nominal depreciation rate as the model implied real exchange rate is not sufficiently volatile. Attempts to reduce the role of the PPP shock by restricting its magnitude resulted in substantially inferior fit. 
The structure of the paper is as follows. We begin by discussing the progress made so far in developing empirical models based on the new open economy macroeconomics (NOEM) paradigm set forth by Obstfeld and Rogoff (1995). We focus our discussion on fullinformation structural estimation methods. Section 3 contains the theoretical model. Section 4 introduces and discusses the Bayesian estimation approach, with a specific focus on misspecification and identification issues. Section 5 describes the construction of the two-country data set and explains the choice of priors based on an extensive presample analysis. The empirical results are summarized in Section 6. The final section concludes and offers directions for future research. Details on the data set and the practical implementation of the empirical analysis are contained in an appendix.

\section{In Search of an Empirical NOEM Model}

The development of theoretical models in the NOEM mold has changed the nature of debate in international finance. While these models have proven to be quite successful at both a conceptual level and in terms of quantitative theory, progress has been slower in developing an empirically viable NOEM model. ${ }^{1}$ In recent years, however, the literature has made large strides toward that goal with the development and widespread use of Bayesian estimation techniques for DSGE models. In a seminal contribution, Leeper and Sims (1994) estimated a DSGE model using full-information, maximum-likelihood methods, with the goal of obtaining an empirical model that is usable for monetary policy analysis. Structural empirical modeling thereby became a viable alternative to nonstructural and partial information methods.

Among others, Schorfheide (2000) pushed the research agenda further by developing useful Bayesian techniques to estimate and evaluate DSGE models in the presence of model misspecification. ${ }^{2}$ Applying these methods, Smets and Wouters (2003) estimated a fully specified, optimization-based model of the Euro area that successfully matched the time series facts. This work has stimulated a host of research in closed economy models. The open economy literature has not been far behind in utilizing Bayesian techniques. In what follows, we discuss the progress that has been made in search of an empirical NOEM model. 
Most estimated NOEM models to date are small open economy (SOE) models. The first paper to use maximum likelihood techniques was Bergin (2003). He estimates and tests an intertemporal SOE model with monetary shocks and nominal rigidities. His results offer mixed support for a benchmark model where prices are assumed to be sticky in the currency of the buyer. However, the benchmark model does a poor job explaining exchange rate movements. Similar contributions along this line are Dib (2003) and Ambler, Dib, and Rebei (2004). While the former shows that a richly parameterized SOE model has forecasting properties that are comparable to those of a vector autoregression (VAR), the latter authors focus on structural parameter estimates to guide optimal monetary policy.

From a modeling point of view, many SOE models can be regarded as an extension of the closed economy New Keynesian framework as detailed in, for instance, Clarida, Galí, and Gertler (1999). This interpretation is supported by the contribution of Galí and Monacelli (2005), who develop a small open economy NOEM that mimics the reducedform structure of the New Keynesian paradigm model. This similarity facilitated the use of already established Bayesian techniques in a closed economy context.

Consequently, Lubik and Schorfheide (2006) estimate a simplified version of the Gali and Monacelli (2005) model to assess whether central banks respond to exchange rate movements. The NOEM framework simply serves as a data-generating process to provide identification restrictions for the estimation of the monetary policy rule. The likelihood function of the DSGE model implicitly corrects for the endogeneity of the regressors in the monetary policy rule. Earlier work on monetary policy in the open economy by Clarida, Galí, and Gertler (1998) has used generalized method of moments (GMM) estimation with a variety of instruments in order to deal with endogeneity. While potentially robust to misspecification, this approach suffers from subtle identification problems that can often lead to implausible estimates. Full-information based methods, on the other hand, use the optimal set of instruments embedded in the model's cross-equation restrictions and make identification problems transparent.

Lubik and Schorfheide (2006) find that among the central banks of Australia, New Zealand, the United Kingdom, and Canada, the latter two consistently respond to exchange rate movements. This conclusion is robust to changes in the sample period, to the type of inflation targeting (forward- versus current-looking), and to the type 
of international relative price variable targeted. Subsequent empirical studies of SOE models include Adolfson, Laseen, Lindé, and Villani (2004); Del Negro (2003); Justiniano and Preston (2004); and Leigh and Lubik (2005).

In contrast to the development of the empirical NOEM literature, the extensive theoretical body of work on open economy DSGE models is largely based on two-country settings. ${ }^{3}$ We believe that this paper is one of the first attempts to estimate a two-country model with Bayesian methods. ${ }^{4}$ Using a maximum likelihood framework, Bergin (2004) is the closest precursor to our paper in terms of scope and purpose. Bergin develops a two-country model that combines features of international real business-cycle models with the NOEM. Specifically, he allows for capital accumulation and investment dynamics to provide richer internal dynamics. Additionally, he assumes that firms can engage in local currency pricing, which allows for deviations from the law of one price, and that international asset markets are incomplete. Since the limearized version of the model would imply nonstationarity due to foreign asset accumulation, he introduces portfolio adjustment costs, which render the dynamics stationary. Bergin applies the model to the United States and the G6 countries and uses data on output, interest rates, inflation, exchange rates, and the current account. He imposes complete symmetry on the model and estimates it on output, inflation, and interest rate differentials. He finds that the model has a similar fit as a VAR and that it produces in-sample, exchange-rate forecasts that are slightly better than a random walk model.

Several institutions have developed large-scale multicountry models with the goal of assisting monetary policy analysis. Examples include the SIGMA model of the Federal Reserve Board of Governors (see Erceg, Guerrieri, and Gust 2005) and the global economic model (GEM) of the International Monetary Fund (see Laxton and Pesenti 2003). However, size creates computational challenges and up to now, these models have been calibrated only to conduct simulation experiments, and have not yet been formally estimated.

Empirical researchers often face difficult choices when attempting to take DSGE models to the data. Even more so than in a closed-economy context, there is an embarrassment of riches in terms of open economy model elements that are designed to capture different aspects of international linkages. Of particular interest are the degree of international risk sharing, the structure of import and export markets, the pricing decisions by producers, and the degree of exchange rate pass-through 
to domestic prices. Additionally, an overriding concern in open economy macro is the ability to explain the behavior of nominal and real exchange rates, their persistence, their comovement with aggregate variables, and their driving forces.

Our approach in this paper is deliberately parsimonious in order to focus on robustness and identification instead of fit. We introduce imperfect pass-through via a conceptually straightforward, yet elegant, import price markup mechanism. This allows us to gauge the contribution of deviations from the law of one price in explaining exchange rate dynamics. We do not utilize the richer multi-sector structure as in Adolfson, Laseén, Lindé, and Villani (2004). Bergin (2003, 2004) has demonstrated empirically that local currency pricing, i.e., price-setting in the currency of the consumer, is an important component for explaining exchange rate movements. We assume producer currency pricing for tractability.

Although there is only weak empirical support for perfect international risk sharing, we impose complete international asset markets. This is in line with most of the theoretical NOEM literature and is likely to have second-order implications only. ${ }^{5}$ In order to capture the persistence in the data, we introduce habit formation in consumption, as in Justiniano and Preston (2004). These authors additionally model inflation indexation in the pricing decision of the firms but find only weak support for this assumption. We also abstract from modeling investment dynamics, as in Bergin (2003).

\section{A Small-Scale Two-Country Model}

We develop a two-country model of the United States ("home") and the Euro area ("foreign") in the mold of the new open economy macroeconomics. We allow for endogenous deviations from purchasing power parity in the short-run but not in the long-run. Specifically, the same good can have different prices depending on where it is sold even after adjusting for exchange rate movements. Producers set prices monopolistically for the domestic as well as the world market in their own currency. Imported goods, however, are subject to price discrimination because monopolistic importers charge a mark-up to consumers at the border. ${ }^{6}$ We assume symmetric preferences and technologies but allow for differences in price-setting, policies, and disturbances affecting each economy. Under the assumption of complete international asset markets, the model has a manageable reduced form but can allow 
for potentially rich exchange rate behavior. In terms of notation, we denote goods produced and activities associated with them in the home and foreign country by $\mathrm{H}$ and $\mathrm{F}$, respectively, while the location of economic activities is indexed by an asterisk $\left({ }^{*}\right)$ for the foreign country, and no index for the home country. For instance, $c_{H}\left(c_{F}^{*}\right)$ is the consumption of the home-(foreign-)produced good in the home (foreign) country.

\subsection{Domestic Households}

The domestic economy is populated by a continuum of households whose preferences are described by an intertemporal utility function ${ }^{7}$ :

$E_{0}\left[\sum_{t=0}^{\infty} \beta^{t}\left[\frac{\left(\mathscr{C}_{t} / A_{W, t}\right)^{1-\tau}}{1-\tau}-N_{\mathrm{f}}\right]\right]$

where $\mathscr{C}_{t}=C_{t}-h \gamma C_{t-1}$ is effective consumption under habit formation and $N_{t}$ is labor input. We assume that habits are internalized by the household. $0 \leq h \leq 1$ is the habit persistence parameter, $\gamma$ is the steady-state growth rate of $A_{W,}, \tau>0$ is the coefficient of relative risk aversion, $0<\beta<1$ is the discount factor. $A_{W, t}$ is a nonstationary worldwide technology shock, where we define $z_{t}=A_{W, t} / \gamma A_{W, t-1}$. The presence of the term $A_{W, t}$ in equation (5.1) implies that households derive utility from effective consumption relative to the level of technology and guarantees that the model has a balanced growth path along which hours worked are stationary, even if $\tau \neq 1$.

$C_{t}$ is an aggregate consumption index:

$C_{i}=\left[(1-\alpha)^{1 / \eta} C_{H, t}^{(\eta-1) / \eta}+\alpha^{1 / \eta} C_{F, t}^{(\eta-1) / \eta}\right]^{\eta /(\eta-1)}$

where $0 \leq \alpha<1$ is the import share and $\eta>0$ is the intratemporal substitution elasticity between home and foreign consumption goods. Households allocate aggregate expenditure based on the demand functions:

$C_{H, t}=(1-\alpha)\left(\frac{P_{H, t}}{P_{t}}\right)^{-\eta} C_{t} \quad$ and $\quad C_{F, t}=\alpha\left(\frac{P_{F, t}}{P_{t}}\right)^{-\eta} C_{t}$

$P_{H, t}, P_{F, t}$ are domestic and foreign goods price indices, and:

$P_{t}=\left[(1-\alpha) P_{H, t}^{1-\eta}+\alpha P_{F, t}^{1-\eta}\right]^{1 /(1-\eta)}$

is the consumption-based price index (CPI). ${ }^{s}$ 
In the aggregate, households face the budget constraint:

$P_{H, t} C_{H, t}+P_{F, t} C_{F, t}+E_{t}\left[Q_{t, t+1} D_{t+1}\right] \leq W_{t} N_{t}+D_{t}-T_{t}$

where $W_{t}$ is the nominal wage for labor services provided to firms, $Q_{t, t+1}$ is the stochastic discount factor used for evaluating consumption streams, and $D_{t}$ represents payments from a portfolio of assets, so that $E_{t}\left[Q_{t, t+1} D_{t+1}\right]$ corresponds to the amount of portfolio purchases at time $t$. Under the assumption of complete asset markets, both domestically and internationally, this portfolio comprises a complete set of statecontingent claims. $T_{t}$ is lump-sum taxes imposed by the government to finance its purchases.

Households maximize the intertemporal utility function subject to a sequence of budget constraints for all $t$. The labor-leisure choice is governed by the intratemporal optimality condition $\lambda_{t}^{-1}=W_{t} / P_{t}$, where $\lambda_{t}$ is the marginal utility of income. Intertemporal consumption choice is given by:

$A_{W, t} \lambda_{t}=\left(\frac{\mathscr{C}_{t}}{A_{W, t}}\right)^{-\tau}-h \gamma \beta E_{t}\left[\frac{A_{W, t}}{A_{W, t+1}}\left(\frac{\mathscr{C}_{t+1}}{A_{W, t+1}}\right)^{-\tau}\right]$

while optimal portfolio choice implies:

$Q_{t, t+1}=\beta \frac{\lambda_{t+1}}{\lambda_{t}} \frac{P_{t}}{P_{t+1}}$

This equation can be used to construct the return on nominal government bonds, i.e., the nominal interest rate:

$R_{t}^{-1}=\beta E_{t}\left[\frac{\lambda_{t+1}}{\lambda_{t}} \frac{P_{t}}{\bar{P}_{t+1}}\right]$

which we take to be the monetary authority's instrument.

\subsection{Domestic Producers}

Domestic differentiated goods are produced by a continuum of monopolistically competitive producers that are subject to Calvo-type price setting. Each period, a fraction $1-\theta_{H}$ of domestic firms set prices optimally, while $\theta_{H}$ firms adjust prices according to the steady-state inflation rate $\pi$, which is common to the home and the foreign economy. Each firm $j \in[0,1]$ maximizes discounted intertemporal profits subject to a downward-sloping demand curve. Demand for a firm's product derives both from domestic sources $C_{H, t}$ and government expenditure 
$G_{H, t}$, as well as from abroad $C_{H, t}^{*}{ }^{9}$ Firms have access to a linear production technology that uses labor as its only input:

$Y_{H, t}(j)=A_{W, t} A_{t} N_{t}(j)$

where $A_{\mathrm{f}}$ is a stationary and country-specific technology shock.

Those firms that are able to re-optimize their price in period $T$ maximize:

$E_{T}\left[\sum_{t=T}^{\infty} \theta_{H}^{t-T} Q_{T, t} \gamma_{H, t}(j)\left[P_{H, T}(j) \pi^{t-T}-P_{H, t} M C_{H, t}\right]\right.$

with respect to $P_{H, T}(j)$ subject to the demand function:

$\gamma_{H, t}(j)=\left(\frac{P_{H, t}(j)}{P_{H, t}}\right)^{-\omega}\left(C_{H, t}+G_{H, t}+C_{H, t}^{*}\right)$

where $M C_{H, t}=W_{t} /\left(A_{W, t} A_{t} P_{H, t}\right)$ is common to all producers due to perfectly competitive labor markets. Firms evaluate revenue streams by the households' stochastic discount factor $Q_{T, t}$. The term $\theta_{H}^{t-T}$ is the probability that the specific firm will not be allowed to adjust its price between periods $T$ and $t$. The solution to the domestic firm's optimization problem implies that prices are set as a (time-varying) mark-up over marginal cost. This results in the familiar Phillips-curve relationship between domestic inflation and marginal cost after aggregation over individual firms and imposing ex-post homogeneity.

\subsection{Domestic Importers}

Following Monacelli (2005), we assume that endogenous deviations from PPP in the short run arise due to the existence of monopolistically competitive importers. Domestic consumers are required to purchase foreign-produced goods from importers that exert market power. Importers purchase foreign goods at world-market prices $P_{F, t}^{*}(j)$ (which are set by their respective producers in their own currency), so that the law of one price holds at the border. Importers sell these goods to domestic consumers and charge a mark-up over their cost, which creates a wedge between domestic and import prices of foreign goods when measured in the same currency. We can define the law of one price (l.o.p.) gap as:

$\psi_{F, t}=\frac{e_{t} P_{F, t}^{*}}{P_{F, t}}$ 
If PPP holds, then $\psi_{F, t} \equiv 1$. Therefore, pass-through from exchange rate movements to the domestic currency prices of imports is imperfect because importers adjust their pricing behavior to extract optimal revenue from consumers.

Similarly to domestic producers, importers operate under Calvostyle price-setting, with $1-\theta_{F}$ importers setting prices optimally each period. Importers maximize the discounted stream of expected profits:

$E_{T}\left[\sum_{t=T}^{\infty} \theta_{F}^{t-T} Q_{T, t} C_{F, t}(j)\left[P_{F, T}(j) \pi^{t-T}-e_{t} P_{F, t}^{*}(j)\right]\right]$

subject to the demand function:

$C_{F, t}(j)=\left(\frac{P_{F, t}(j)}{P_{F, t}}\right)^{-\omega} C_{F, t}$

where we assume that domestic government purchases cannot fall on foreign-produced goods. Note also that the marginal cost of purchasing imports is the l.o.p. gap for the specific good. Consequently, importers set domestic currency prices of foreign goods as a (timevarying) mark-up over $\psi_{F, t}$. These endogenous deviations from PPP then result in a Phillips-curve relationship between import-price inflation and the l.o.p. gap.

\subsection{The Foreign Economy}

We assume that home and foreign economies are symmetric in terms of preferences and technology, but they can differ in price-setting and monetary policy. The equations describing the foreign economy are therefore the same as for home, but variables and parameters with asterisks are properly substituted. We can define the real exchange rate as:

$s_{t}=\frac{e_{t} P_{t}^{*}}{P_{t}}$

Symmetry implies that the foreign real exchange rate $s_{t}^{*}=s_{t}^{-1}$. On the other hand, the terms of trade differ between the two countries by the l.o.p. gaps. The domestic terms of trade, that is, the price of exports in terms of imports measured in domestic currency, are:

$q_{t}=\frac{P_{H, t}}{P_{F, t}}$ 
while the foreign terms of trade are:

$q_{t}^{*}=\frac{P_{E, t}^{*}}{P_{H, t}^{*}}$

Using the definition of the l.o.p. gaps, we can derive the expression:

$\frac{\psi_{F, t}}{q_{t}}=\frac{q_{t}^{*}}{\psi_{H, i}^{*}}$

Home and foreign terms of trade coincide (inversely) only when passthrough is perfect.

\subsection{Risk-Sharing, Market Clearing, and Equilibrium}

Complete international asset markets imply perfect risk-sharing between households in the two countries. In equilibrium, stochastic discount factors in the two countries have to be equalized, which leads to the following condition:

$\beta \frac{\lambda_{t+1}}{\lambda_{t}} \frac{P_{t}}{P_{t+1}}=Q_{t, t+1}=\beta \frac{\lambda_{t+1}^{*}}{\lambda_{t}^{*}} \frac{P_{t}^{*}}{P_{t+1}^{*}} \frac{e_{t}}{e_{t+1}}$

Goods market clearing requires that:

$Y_{H, t}=C_{H, t}+G_{t}+C_{H, t}^{*} \quad$ and $\quad Y_{F, t}^{*}=C_{F, t}^{*}+G_{t}^{*}+C_{F, t}$

Moreover, we assume that both countries are of equal size and that initial asset positions are zero. This implies balanced trade in value terms in the steady state and no net asset accumulation by any country.

\subsection{Linearization}

We proceed by (log-) linearizing the model equations around the balanced growth path. Our model imposes common steady-state real interest rates, inflation rates, growth rates, and technologies. Since the model contains a nonstationary component in the form of worldwide productivity growth, we de-trend the affected variables by their specific growth components beforehand. In our empirical analysis, we exploit the properties of the model as a variant of the New Keynesian monetary policy model that has attracted a lot of recent interest due its interpretability and tractability. In what follows therefore, we briefly discuss the key structural equations. All variables are in log-deviations from the steady state, where $\tilde{x}_{t}=\log x_{t}-\log \bar{x}$. 
A linear approximation to the solution of the domestic firms' pricesetting problems results in a Phillips-curve type relationship between domestic inflation and marginal cost:

$\tilde{\pi}_{H, t}=\beta E_{\mathrm{t}} \tilde{\pi}_{H, t+1}+\kappa_{H} \widetilde{m}_{H, t}$

where $\kappa_{H}=\left(\left(1-\theta_{H}\right) / \theta_{H}\right)\left(1-\theta_{H} \beta\right)$. Using the condition for laborleisure choice, the marginal cost term can be expressed as $\widetilde{m c}_{H, t}=$ $-\tilde{\lambda}_{t}-\alpha \tilde{q}_{t}-\tilde{A}_{t}$. The term $\tilde{\lambda}_{t}$ is the marginal utility of income, which evolves according to:

$-\tilde{\lambda}_{t}=\frac{\tau}{1-h \beta} \tilde{\mathscr{C}}_{t}-\frac{h \beta}{1-h \beta} E_{t}\left[\tau \tilde{\mathscr{C}}_{t+1}+\tilde{z}_{t+1}\right]$

where the law of motion for the habit stock is:

$$
(1-h) \tilde{\mathscr{C}}_{t}=\tilde{c}_{t}-h \tilde{c}_{t-1}+h \tilde{z}_{t}
$$

For $h=0$, the model reduces to standard consumption preferences. Recall that $\tilde{z}_{i}=\Delta \tilde{A}_{W, t}$. Worldwide shocks do not affect marginal costs (only country-specific shocks do), but they change the intertemporal consumption trade-off as evidenced by habit dynamics and the Eulerequation:

$-\tilde{\lambda}_{t}=-E_{t} \tilde{\lambda}_{t+1}-\left(\tilde{R}_{t}-E_{t} \tilde{\pi}_{t+1}\right)+E_{t} \tilde{z}_{t+1}$

The price-setting problem of importers reduces to a Phillips-curve type relation between import price inflation and the l.o.p. gap:

$\tilde{\pi}_{F, t}=\beta E_{t} \tilde{\pi}_{F, t+1}+\kappa_{F} \tilde{\psi}_{F, t}$

where $\kappa_{F}=\left(\left(1-\theta_{F}\right) / \theta_{F}\right)\left(1-\theta_{F} \beta\right)$. CPI-inflation can be derived using the definition:

$\tilde{\pi}_{t}=\alpha \tilde{\pi}_{F, t}+(1-\alpha) \tilde{\pi}_{H, t}$

and the terms of trade evolve according to:

$\tilde{q}_{t}=\tilde{q}_{t-\mathbf{1}}+\tilde{\pi}_{H, t}-\tilde{\pi}_{F, t}$

Inflation dynamics therefore depends on domestic driving forces as well as international relative price movements and endogenous deviations from PPP in the form of imperfect pass-through. The real exchange rate behaves according to:

$\tilde{s}_{t}=\tilde{\psi}_{F, t}-(1-\alpha) \tilde{q}_{t}-\alpha \tilde{q}_{t}^{*}$ 
and captures the distortions introduced by the 1.o.p. gap as well as movements in each country's own terms of trade. Using the definition of the real exchange rate also allows us to derive nominal exchange rate dynamics:

$$
\Delta \tilde{e}_{t}=\tilde{\pi}_{t}-\tilde{\pi}_{l}^{*}+\Delta \tilde{s}_{t}
$$

The (linearized) asset pricing equation for nominal bonds implies that the interest rate differential is related to expected exchange rate depreciation, in other words, uncovered interest parity (UIP):

$\tilde{R}_{t}-\tilde{R}_{t}^{*}=E_{t} \Delta \tilde{e}_{t+1}$

Furthermore, international risk-sharing implies a relationship among marginal utilities across countries adjusted for purchasing power:

$\tilde{\lambda}_{t}=\tilde{\lambda}_{t}^{*}-s_{t}$

The goods market clearing condition:

$\tilde{y}_{H, t}=\tilde{c}_{t}-\tilde{g}_{t}-\frac{\alpha}{\tau} \tilde{s}_{t}-\alpha(1-\alpha) \eta\left(\tilde{q}_{t}-\tilde{q}_{t}^{*}\right)$

shows how output is affected by demand and relative prices. Demand disturbances in the form of government expenditure shocks $\tilde{g}_{t}$ therefore affect output directly and not via changing marginal rates of substitution in consumption and leisure.

The model is closed by specifying monetary policy. We assume that central banks in both countries adjust the nominal interest rate in response to deviations of inflation, a measure of output, and exchange rate depreciation from their respective targets:

$\tilde{R}_{t}=\rho_{R} \tilde{R}_{t-1}+\left(1-\rho_{R}\right)\left[\psi_{1} \tilde{\pi}_{t}+\psi_{2}\left(\Delta \tilde{y}_{t}+\tilde{z}_{t}\right)+\psi_{3} \Delta \tilde{e}_{t}\right]+\epsilon_{R, t}$

The monetary policy rule is of the standard Taylor-type, with the exception that the central bank responds to deviations of output growth from the mean growth rate, $\gamma$, instead of a measure of the output gap.

Once the equations describing the foreign economy are added, the log-linearized model consists of twenty-one equations in endogenous variables, and five equations describing the evolution of the exogenous autoregressive shocks:

$$
\begin{array}{ll}
\tilde{z}_{t}=\rho_{z} \tilde{z}_{t-1}+\epsilon_{z, t} & \tilde{A}_{t}=\rho_{A} \tilde{A}_{t-1}+\epsilon_{A, t} \quad \tilde{A}_{t}^{*}=\rho_{A^{*}} \tilde{A}_{t-1}^{*}+\epsilon_{A^{*}, t} \\
\tilde{G}_{t}=\rho_{G} \tilde{G}_{t-1}+\epsilon_{G, t} & \tilde{G}_{t}^{*}=\rho_{G^{*}} \tilde{G}_{t-1}^{*}+\epsilon_{G^{*}, t}
\end{array}
$$


Moreover, there are innovations in each country's monetary policy rule denoted by $\epsilon_{R, t}$ and $\epsilon_{R^{*}, t}$. Given these exogenous processes, the model is then solved using the methods described in Sims (2002). The closed economy version of the model is obtained by setting $\alpha=0$ and combining equations (5.20), (5.21), (5.22), (5.23), (5.25), (5.31), and (5.32).

\section{Why a Bayesian Approach?}

Our empirical analysis focuses on three broad questions, which are directly related to estimates of the structural parameters and to the dynamic properties of the two-country model. First, we examine the magnitude of nominal rigidities, captured by the Calvo parameters. The rigidities in the import sectors, controlled by $\theta_{F}$ and $\theta_{H}^{*}$, determine the degree of exchange rate pass-through and play an important role for the transmission of shocks across country borders. Second, we estimate monetary policy rules for the United States and the Euro area and study the propagation of monetary policy shocks. Unanticipated changes in monetary policy appear as innovations in the interest rate feedback rule in equation (5.32). The estimation of the policy coefficients and hence the identification of the monetary policy shocks is hindered by the joint endogeneity of the variables in the interest-rate feedback rule. Finally, we use the open economy model to determine the relative importance of the various nominal and real structural shocks for exchange rate fluctuations.

The Bayesian approach pursued in this paper has three main characteristics. First, unlike GMM estimation of monetary policy rules and first-order conditions, the Bayesian analysis is system-based and fits the solved DSGE model to a vector of aggregate time series. Second, the estimation is based on the likelihood function generated by the DSGE model rather than, for instance, the discrepancy between DSGE model impulse response functions and identified VAR impulse responses as in Rotemberg and Woodford (1997) and Christiano, Eichenbaum, and Evans (2005). Third, prior distributions can be used to incorporate additional information into the parameter estimation.

Any estimation method for DSGE models has to address the problem of potential model misspecification and lack of identification. DSGE models impose potentially invalid cross-coefficient restrictions on the time series representation of $y_{t}$, often resulting in poor out-of-sample fit relative to VARs. For instance, in order to keep our two-country 
model transparent and the estimation tractable, we assumed symmetric tastes across countries, a common trend in productivity, perfect risk sharing, uncovered interest rate parity, and we abstracted from capital accumulation. While in a closed economy setting, more elaborate models such as Smets and Wouters (2003) had some success in closing the gap between model and reality, misspecification remains a concern even for large-scale DSGE models, as documented in Del Negro, Schorfheide, Smets, and Wouters (2004).

If different parameterizations of a DSGE model have distinct substantive implications but are observationally equivalent, then the model is not fully identified. Unlike the context of linear simultaneous equations models or vector autoregressions, there are no easily verifiable identification conditions for DSGE models available because the mapping from the structural parameters into the reduced-form state space representation is highly nonlinear. The use of large-scale models that relax some of the unrealistic restrictions imposed by their smaller cousins potentially amplifies identification problems. Hence, it is important that a DSGE model estimation procedure generates coherent inference, even if some parameters are not identifiable, and can incorporate additional information from other data sets. After some preliminary remarks on the structure of linearized DSGE models, the remainder of this section will focus on how Bayesian inference can be used to cope with misspecification and identification problems.

\subsection{Preliminaries}

The log-linearized DSGE model can be written as a linear rational expectations (LRE) system of the form:

$\Gamma_{0}(\theta) s_{t}=\Gamma_{1}(\theta) s_{t-1}+\Gamma_{\epsilon}(\theta) \epsilon_{t}+\Gamma_{\eta}(\theta) \eta_{t}$

Here, $s_{t}$ denotes the vector of model variables such as $\tilde{y}_{t}, \tilde{\pi}_{t}, \tilde{R}_{t}$. The vector $\epsilon_{t}$ stacks the innovations of the exogenous processes, and $\eta_{t}$ is composed of rational expectations forecast errors. ${ }^{10}$ The dynamics of the exogenous shock processes are absorbed in the definition of the $\Gamma$ matrices, and $\theta$ collects the structural parameters of the model. The solution to equation (5.34) can be expressed as:

$\varsigma_{t}=\Phi_{1}(\theta) s_{t-1}+\Phi_{\varepsilon}(\theta) \epsilon_{t}$

A measurement equation then relates the model variable $s_{t}$ to a vector of observables $y_{t}$ : 
$y_{t}=A(\theta)+B s_{t}$

In our application, $y_{t}$ is composed of output growth, inflation, and nominal interest rates for the United States and Euro area, as well as the US\$-Euro exchange rate. $B$ does not depend on $\theta$ because it merely selects elements of $s_{t} . A(\theta)$ captures the mean of $y_{t}$, which is related to the underlying structural parameters.

In practice, if $y_{t}$ is predicted based on its lagged values, then its forecast error covariance matrix is nonsingular. Hence, any DSGE model that generates a rank-deficient covariance matrix for $y_{t}$ is clearly at odds with the data. So far, our model has seven shocks and can indeed generate a forecast error covariance matrix that is full rank. The larger the dimension of $y_{t}$, the more shocks have to be introduced into the model. For instance, Smets and Wouters (2003) include investment, consumption, hours worked, and wages in addition to output, inflation, and interest rates. As a consequence, they have to use a highdimensional vector $\epsilon_{\mathrm{f}}$ that includes shocks to the mark-up of the monopolistically competitive firms, the shadow value of installed capital, and the disutility of labor. ${ }^{11}$ Other authors, referring to Sargent (1989), have added shocks not to the LRE system in equation (5.34) but rather to the measurement equation (5.36), thus avoiding a structural interpretation of these additional sources of uncertainty. These additional error terms are often called measurement errors, which is a misnomer because the shocks are designed to capture an obvious form of model misspecification.

Bayesian analysis provides a powerful framework for DSGE model estimation and inference that is attractive both at a conceptual level as well as from a practical perspective. Let $Y=\left\{y_{t}\right\}_{t=1}^{T}$. We will collect the DSGE model parameters in the vector $\theta$. The likelihood function $\mathscr{L}(\theta \mid Y)$ is combined with a prior density $p(\theta)$ to form a posterior density $p(\theta \mid Y)$ :

$p(\theta \mid Y) \propto \mathscr{L}(\theta \mid Y) p(\theta)$

where $\propto$ denotes proportionality. Bayesian procedures tend to have many desirable statistical properties and allow for coherent inference and decision making under model and parameter uncertainty, as discussed in textbooks such as Robert (1994). We want to emphasize two different aspects of Bayesian inference, namely, its properties under potential misspecification and lack of identification. In the subsequent discussion, we will assume that the researcher has, in addition to $Y$, ac- 
cess to some data set $X$ that is potentially informative with respect to $\theta$. $X$ might contain a pre-sample of $y_{t}{ }^{\prime} \mathrm{s}$, other macroeconomic time series, or micro-level observations.

\subsection{Misspecification}

The presence of misspecification complicates econometric inference and decision making. In this paper, we are mostly interested in the estimation of structural parameters, such as the response of central banks to exchange rates, or the substitution elasticity between home and foreign goods, and moving average representation of the time series $y_{t}$ in terms of the structural shocks $\epsilon_{t}$. DSGE model misspecification can take many forms, including omitted nonlinearities, misspecified structural relationships due to incorrect preferences or technologies, or misspecification due to omitted or wrongly specified exogenous processes.

Once we acknowledge that our econometric model provides merely an approximation to the law of motion of the time series $y_{t}$, then it seems reasonable to allow for the possibility that there does not exist one single parameter vector $\theta_{0}$ that delivers, say, the "true" substitution elasticity between home and foreign goods and the most precise impulse responses to a monetary policy shock. All formal and informal estimation procedures implicitly use a measure of discrepancy between the "true" law of motion and the approximating model. Not surprisingly, under model misspecification, different measures of discrepancy tend to deliver different parameter estimates. Likelihoodbased methods, for instance, search for values of $\theta$ under which the approximating model generates good time series forecasts. ${ }^{12}$

One interpretation of the calibration approach advocated by Kydland and Prescott $(1982,1996)$ is that there exists ample evidence on $\theta_{0}$ both through the long-run properties of $y_{t}$ and from other data sets, which we denoted by $X$. As mentioned above, $X$ might contain microlevel observations on household and firm behavior. This evidence is translated into calibrated values of $\theta$ that are used to parameterize the DSGE model to address the questions of interest. In the absence of model misspecification and the presence of abundant out-of-sample evidence $X$, likelihood-based estimation methods should generate the same parameter values that calibrators choose, and vice versa: parameter values obtained from a calibration analysis should yield high likelihoods. The experience of two decades of calibration and one decade of estimation has been, unfortunately, that there is neither enough information in $X$ to unambiguously pin down $\theta_{0}$, nor that parameter values 
obtained from micro-level studies necessarily lead to large values of likelihood functions.

In a Bayesian framework, the likelihood function in equation (5.37) is re-weighted by the prior density $p(\theta)$, and the prior can bring to bear information $X$ that is not contained in the sample $Y$. Unlike in a maximum likelihood approach that uses some of the extraneous information to fix elements of the parameter vector $\theta$, the prior density allows us to weigh information about different parameters according to its reliability. Strong microeconometric evidence about the frequency with which firms change their prices or information on the degree of exchange-rate pass-through can be captured in a tight prior distribution for the corresponding model parameters. Since priors are always subject to revision, the shift from prior to posterior distribution can be an indicator of the tension between the micro-level and time series information. If the likelihood function peaks at a value that is at odds with the information in $X$, then the marginal data density, defined as:

$p(Y)=\int \mathscr{L}(\theta ; Y) p(\theta) d \theta$

will be substantially lower than the marginal data density computed under an alternative, more diffuse prior. Marginal data densities can be used to compare different Bayes models, where a Bayes model consists of a likelihood function and a prior distribution. Illustrating how the marginal data density changes as the prior is modified can also highlight tensions between different sources of information.

The overall fit of a DSGE model can be assessed by comparison to a reference model. In this paper, we simply compute marginal data densities for different versions of Bayesian VARs with Minnesota-type priors and compare them to marginal data densities computed from the estimated two-country model. More elaborate methods are available but not pursued in this paper. For instance, in Del Negro, Schorfheide, Smets, and Wouters (2004), the assessment of fit is not based on a VAR with Minnesota prior. Instead the DSGE model itself is used to construct a prior distribution for the VAR coefficients. The procedure has the interpretation that the restrictions imposed by the DSGE model on the VAR representation of $y_{t}$ are relaxed to the extent that the deviation from the restriction improves the marginal data density of the resulting specification. A comparison of DSGE model impulse 
responses and identified responses from the so-called DSGE-VAR can yield insights about the nature of the misspecification. A procedure that allows for a loss-function-based comparison of multiple, potentially misspecified DSGE models has been developed in Schorfheide (2000).

The two most popular altematives to likelihood-based inference are (1) parameter estimation based on the minimization of the discrepancy between impulse responses of DSGE models and identified vector autoregressions and (2) single-equation GMM estimation. Impulse response function matching tries to cope with model misspecification by leaving most of the exogenous shocks unspecified. Its disadvantage is that it requires correctly identified and precisely estimated VAR impulse responses to, for instance, a monetary policy or a technology shock. Moreover, it does not provide an overall measure of time series fit of the DSGE model.

Single-equation approaches also address the problem of model misspecification by leaving parts of the DSGE model unspecified. Consider the price-setting equation [equation (5.20)] for U.S. producers in our two-country model. The system-based Bayesian estimation approach treats inflation $\tilde{\pi}_{H, t}$ and marginal costs $\widetilde{m c}_{t}$ as latent variables. It uses the model restrictions stemming from the production function and the equilibrium prices, together with the observations on CPI inflation, output growth, interest rates, and nominal exchange rates, to infer inflation and marginal costs in the U.S. production sector. A singleequation GMM estimation of the price-setting equation would require time series observations for $\tilde{\pi}_{H, t}$ and $\widetilde{m c}_{t}$. The use of direct observations on marginal costs is likely to deliver a more reliable estimate of $\kappa_{H}$, but the single-equation approach tends to mask identification problems and the model's potential inability to predict the movements of these additional observations.

In the estimation of the monetary policy rule, the likelihood function adjusts the endogenous regression equation [equation (5.32)] by the conditional expectation term $E\left[\epsilon_{R, t} \mid \tilde{\pi}_{\mathrm{t}}, \tilde{y}_{t}-\tilde{y}_{t-1}+\tilde{z}_{\mathrm{t}}, \Delta \tilde{e}_{\mathrm{t}}\right]$. In a GMM approach, on the other hand, one would choose a set of instrumental variables, e.g., lagged endogenous variables, that are orthogonal to the current monetary policy shock $\epsilon_{t}$. The likelihood-based approach exploits the cross-equation restrictions to construct the conditional expectation of the policy shock. This can lead to sharper inference if the model is well specified, or it might contaminate the parameter estimates if the conditional expectation is poorly specified. 
Most important, single-equation estimates do not provide an overall measure of time series fit of the DSGE model. Hence, the reliability of, for instance, impulse response functions constructed based on parameter estimates that have been obtained with single-equation estimation methods are difficult to assess. Since the exogenous shocks that generate business cycles are typically left unspecified, it is not possible to disentangle the relative importance of the various shocks for the fluctuations of the endogenous variables. In the presence of rational expectations, the idea of single-equation estimation is often fundamentally flawed because identification of the structural parameters can be achieved only if the remainder of the system is sufficiently restricted. We will elaborate on this point in the following subsection.

\subsection{Identification}

Identification problems can arise due to a lack of informative observations or, more fundamentally, from a probability model that implies that different values of structural parameters lead to the same joint distribution for the observables $Y$. We will provide a simple example for each case.

Suppose we are interested in estimating the degree of exchange rate pass-through, which in our two-country model is tied to the parameters $\theta_{F}$ and $\theta_{H}^{*}$. In the absence of nominal rigidities in the import sector, pass-through is perfect. We would expect that the degree of passthrough is best measured through the dynamics of import prices. Nonstructural studies of exchange rate pass-through often regress import prices on measures of exchange rate variation, e.g., Campa and Goldberg (2004). Smets and Wouters (2002) implicitly estimate the degree of nominal rigidity in the import sector of a small open economy model by matching DSGE model impulse responses to VAR impulse responses, whereby the response of import prices to an exchange rate shock plays an important role in determining the degree of passthrough. The estimation results presented subsequently are based on U.S. and Euro area CPI inflation. While the degree of pass-through also affects the dynamics of CPI inflation, the choice not to use direct information on import prices will make it more difficult to identify the degree of pass-through.

Rational expectations models can generate delicate identification problems that are very difficult to detect in larger systems since the mapping from the vector of structural parameters $\theta$ into the state-space 
representation [equations (5.35) and (5.36)] that determines the joint probability distribution of $Y$ is highly nonlinear and typically can only be evaluated numerically. Consider the following two models, in which $y_{t}$ is the observed endogenous variable and $u_{t}$ is an unobserved shock process. In model $\mathscr{M}_{1}$, the $u_{t}$ 's are serially correlated:

$\mathscr{M}_{1}: \quad y_{t}=\frac{1}{\alpha} \mathbb{E}_{\mathrm{t}}\left[y_{t+1}\right]+u_{t} \quad u_{\mathrm{f}}=\rho u_{t-1}+\epsilon_{t} \sim \operatorname{iid}\left(0, \sigma^{2}\right)$

In model $\mathscr{A}_{2}$, the shocks are serially uncorrelated, but we introduce a backward-looking term $\phi y_{t-1}$ on the right-hand-side, as is often done in the new Keynesian Phillips curve literature:

$$
\mathscr{H}_{2}: \quad y_{t}=\frac{1}{\alpha} \mathbb{E}_{t}\left[y_{t+1}\right]+\phi y_{t-1}+u_{t} \quad u_{t}=\epsilon_{t} \sim \ddot{i i d}\left(0, \sigma^{2}\right)
$$

Under $\mathscr{M}_{1}$, the equilibrium law of motion becomes:

$\mathscr{M}_{1}: \quad y_{t}=\rho y_{t-1}+\frac{1}{1-\rho / \alpha} \epsilon_{t}$

whereas under the backward-looking specification: ${ }^{13}$

$\mathscr{H}_{2}: \quad y_{t}=\frac{1}{2}\left(\alpha-\sqrt{\alpha^{2}-4 \phi \alpha}\right) y_{t-1}+\frac{2 \alpha}{\alpha+\sqrt{\alpha^{2}-4 \phi \alpha}} \epsilon_{t}$

Models $\mathscr{M}_{1}$ and $\mathscr{H}_{2}$ are observationally equivalent. The model with the backward-looking component is distinguishable from the purely forward-looking specification only under a strong a priori restriction on the exogenous component, namely, $\rho=0$. Although $\mathscr{M}_{1}$ and $\mathscr{M}_{2}$ will generate identical reduced form forecasts, the effect of changes in $\alpha$ on the law of motion of $y_{t}$ is different in the two specifications. While Bayesian analysis does not alter the likelihood functions associated with models $\mathscr{M}_{1}$ and $\mathscr{M}_{2}$, it can bring to bear additional information $\mathrm{X}$ about the parameters that may help to discriminate between the two specifications.

For $\mathscr{M}_{1}$, it is easy to see that $\alpha$ and the standard deviation of $\epsilon_{\mathrm{f}}$ are not separately identifiable. The likelihood function conditional on $\rho$ is flat for values of $\alpha$ and $\sigma$ such that $\sigma /(1-\rho / \alpha)$ is constant. More generally, suppose that the generic parameter vector $\theta$ of a probability model can be partitioned into $\theta=\left[\theta_{1}^{\prime}, \theta_{2}^{\prime}\right]^{\prime}$, and the likelihood function is flat in the direction of $\theta_{2}: \mathscr{L}(\theta \mid Y)=\overline{\mathscr{L}}\left(\theta_{1} \mid Y\right)$. Straightforward manipulations with Bayes theorem lead to: 
$p(\theta \mid Y)=p\left(\theta_{1} \mid Y\right) p\left(\theta_{2} \mid \theta_{1}\right) \propto \overline{\mathscr{L}}\left(\theta_{1} \mid Y\right) p\left(\theta_{1}, \theta_{2}\right)$

First, a proper prior $p\left(\theta_{1}, \theta_{2}\right)$ can introduce curvature into the objective function that facilitates numerical maximization and the use of Markov Chain Monte Carlo methods to generate draws from the posterior distribution. Second, there is updating of the marginal distribution of $\theta_{1}$ but not of the conditional distribution of $\theta_{2} \mid \theta_{1}{ }^{14}$ Nevertheless, the posterior distribution is well defined as long as the joint prior distribution of $\theta$ integrates to 1 . Hence, a comparison of priors and posteriors can provide insights about the extent to which the data provide information about the parameters of interest.

Finally, consider the attempt to answer the question whether there is backward-looking behavior via GMM analysis. Let $\eta_{t}$ be the rational expectations forecast error associated with $y_{t}$ and write:

$y_{t}-\alpha y_{t-1}+\alpha \phi y_{t-2}=\eta_{t}-\alpha u_{t-1}$

The presence of $u_{t-1}$ on the right-hand-side suggests that $y_{t}$ has to be lagged by at least two periods to obtain valid instruments. It is straightforward to verify that under $\mathscr{M}_{1} \hat{\alpha} \stackrel{p}{\rightarrow} \rho$ and under $\mathscr{M}_{2} \hat{\alpha} \stackrel{p}{\rightarrow}(1 / 2)$.

$\left(\alpha-\sqrt{\alpha^{2}-4 \phi \alpha}\right)$, where $\stackrel{p}{\rightarrow}$ denotes convergence in probability. Under both specifications $\widehat{\alpha \phi} \stackrel{p}{\rightarrow} 0$. Hence, the GMM estimates are inconsistent in this example.

The identification of rational expectation systems and DSGE models more generally is typically possible only under strong a priori restrictions on the model and the exogenous driving processes. This point has been emphasized by Sims (1980), and in recent years in the context of indeterminacy by Lubik and Schorfheide (2004) and Beyer and Farmer (2004). Limited information approaches that try to avoid auxiliary assumptions are often subject to hidden identification problems, as illustrated in the stylized example above. Hence, we advocate the use of a system-based estimation approach that spells out all auxiliary assumptions, constructs a likelihood function, and combines the sample information $Y$ with out-of-sample information $X$ summarized in a prior distribution.

\section{Data and Priors}

We interpret our theoretical two-country model as representing the economies of the United States and the Euro area. The two regions are roughly the same size and have a similar per capita income; unlike 
other groups of countries such as the OECD, the Euro area can be viewed as a unified economic region. Even before European Monetary Union, monetary policy in Europe was guided by the Deutsche Bundesbank within a system of fixed exchange rates. Moreover, closed economy versions of New Keynesian DSGE models have been estimated for both the United States and the Euro area and can serve as a benchmark for the analysis of the two-country model developed in this paper.

Our empirical analysis is based on output growth, inflation, and nominal interest rate series for the United States and the Euro area, as well as data on nominal depreciation rates. Most of the U.S. data were extracted from the FRED 2 database maintained by the Federal Reserve Bank of St. Louis. The Euro area time series comes from the database underlying the Area Wide Model of the European Central Bank. In addition, we construct a synthetic US\$-Euro exchange rate series for the time period prior to the introduction of the Euro in $1999 .{ }^{15}$ Details on the construction of the data set are provided in Section 8.1 of the appendix. The estimation results reported in Section 6 are based on a sample from 1983:I to 2002:IV.

\subsection{A Preliminary Look at the Data}

The top panel of figure 5.1 plots the ratio of per capita gross domestic product (GDP) in the United States and the Euro area. According to the DSGE model, the technology processes in the two regions have a common stochastic trend. Since all the other shocks in the model are stationary, the output ratio should be stationary. While the series plotted in the first panel appears fairly persistent, its autocorrelation is 0.85 and a conventional Dickey-Fuller test rejects the null hypothesis of a unit root. Thus, the common trend assumption does not seem to be at odds with the data.

The nominal depreciation rate is depicted in the bottom panel of figure 5.1. The depreciation rate is very volatile, in particular compared to quarter-to-quarter interest rate differentials $\tilde{R}_{t-1}-\tilde{R}_{t-1}^{*}$ and quarter-toquarter inflation differentials $\tilde{\pi}_{t}-\tilde{\pi}_{i}^{*}$. Our model imposes uncovered interest rate parity, that is:

$$
E_{t-1}\left[\Delta \tilde{e}_{t}\right]=\tilde{R}_{t-1}-\tilde{R}_{t-1}^{*}
$$

According to the data, the interest rate differential, and hence the conditional mean of the nominal depreciation rate, shows very little time variation. Thus, in order to fit the exchange rate data, the DSGE model 

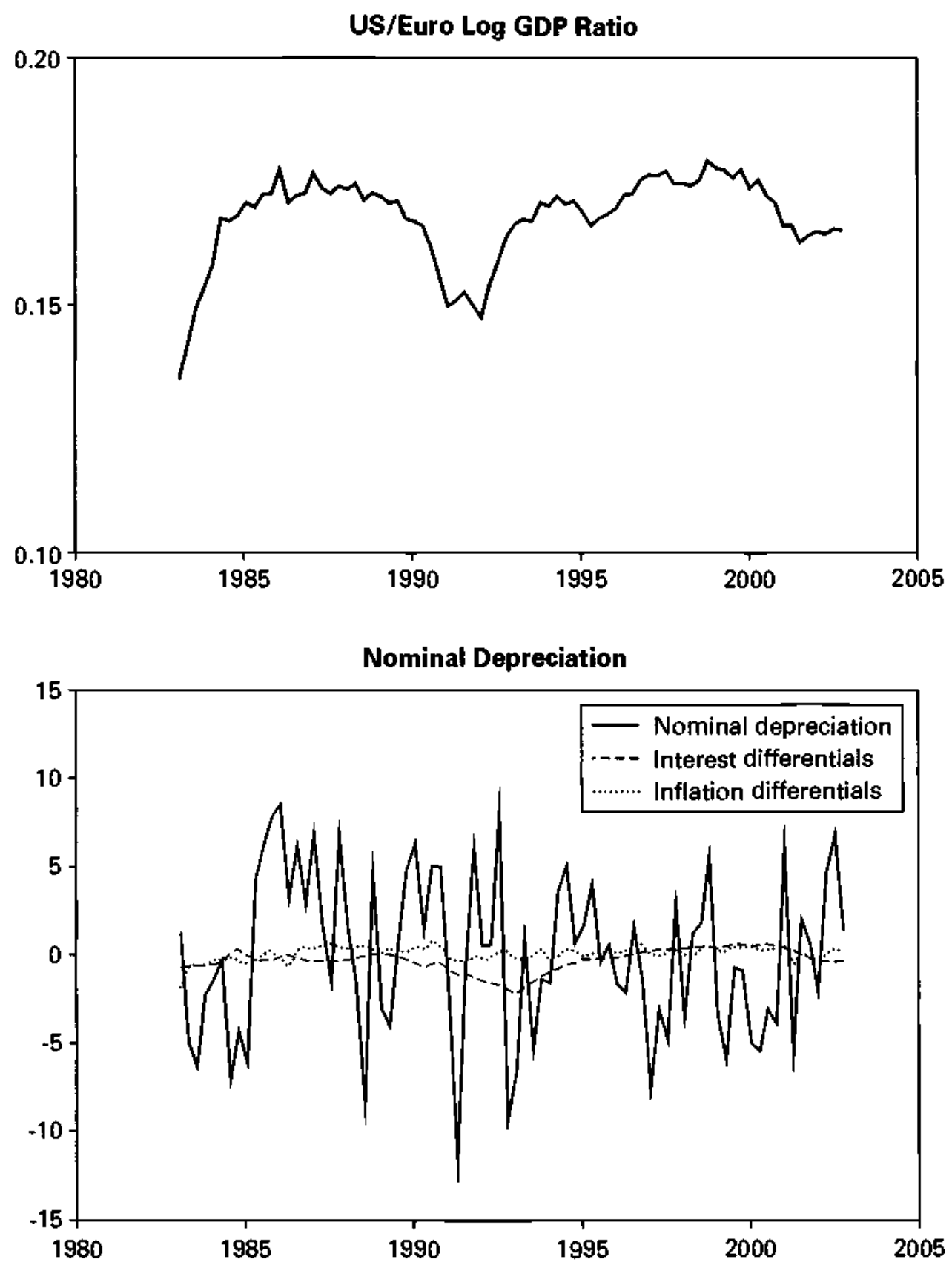

Figure 5.1

Output, Inflation, Interest Rates, and Exchange Rates

Note: Top panel: log real per capita GDP ratio for United States versus Euro area. Bottom panel: nominal exchange rate depreciation, quarter-to-quarter interest rate differential $\tilde{R}_{t-1}-\tilde{R}_{i-1}^{*}$, and quarter-to-quarter inflation differential $\tilde{\pi}_{t}-\tilde{\pi}_{l}^{*}$. 
has to generate a mapping from the structural shocks into unanticipated movements of the depreciation rates that can explain the large fluctuations of $\Delta \tilde{e}_{t}$.

We also impose the PPP relationship:

$$
\Delta \tilde{e}_{t}=\Delta \tilde{s}_{t}+\left(\tilde{\pi}_{t}-\tilde{\pi}_{t}^{*}\right)
$$

Figure 5.1 shows that the actual inflation differential is fairly smooth and that most of the nominal exchange rate fluctuations are aligned with movements of the real exchange rate. It is well known that the current generation of NOEM models has difficulties reproducing the observed volatility of the real exchange rate (see, for instance, Chari, Kehoe, and McGrattan 2002). Therefore, we introduce a shock to the PPP equation:

$\Delta \tilde{e}_{t}=\Delta \tilde{s}_{t}+\left(\tilde{\pi}_{t}-\tilde{\pi}_{t}^{*}\right)+\epsilon_{\mathrm{E}, t}$

This shock essentially captures model misspecification. If the estimated variance of $\epsilon_{E, t}$ is small, we can conclude that the model can explain most of the observed real exchange rate fluctuations.

\subsection{Presample Analysis and Prior Distributions}

In principle, priors can be gleaned from personal introspection to reflect strongly held beliefs about the validity of economic theories, but in practice, most priors are chosen based on some observations, denoted by $X$ in Section 4, that are available in addition to the estimation sample $Y$. We will subsequently motivate the choice of most of our priors based on a presample of observations from 1970:I to 1982:IV. The prior distributions for the price stickiness parameters are loosely chosen based on micro-econometric studies of price-setting behavior. The marginal prior distributions for the parameters of the NOEM model are summarized in tables 5.1 and 5.4. We assume all parameters to be a priori independent.

For both the United States and the Euro area, we are fitting $\operatorname{AR}(1)$ models to inflation rates, import shares, and ex post real interest rates. The estimated means are used to guide the choice of prior means for the steady-state real interest $r$, the import share parameter $\alpha$, and steady-state inflation rates $\pi$, and $\pi^{*}$. We also estimate a common stochastic trend model for U.S. and Euro area output data:

$\Delta \tilde{y}_{t}=\gamma+\Delta \tilde{A}_{t}+z_{t} \quad \Delta \tilde{y}_{t}^{*}=\gamma+\Delta \tilde{A}_{t}^{*}+z_{t}$ 
Table 5.1

Prior Distribution (Benchmark)

\begin{tabular}{|c|c|c|c|c|}
\hline Name & Domain & Density & Para (1) & Para (2) \\
\hline$\theta_{H}$ & {$[0,1)$} & Beta & 0.50 & 0.15 \\
\hline$\theta_{F}$ & {$[0,1)$} & Beta & 0.50 & 0.15 \\
\hline$\theta_{H}^{*}$ & {$[0,1)$} & Beta & 0.75 & 0.15 \\
\hline$\theta_{\xi}^{*}$ & {$[0,1)$} & Beta & 0.75 & 0.15 \\
\hline$\tau$ & $\mathbb{R}^{+}$ & Gamma & 2.00 & 0.50 \\
\hline$h$ & {$[0,1)$} & Beta & 0.30 & 0.10 \\
\hline$\alpha$ & {$[0,1)$} & Beta & 0.12 & 005 \\
\hline$\eta$ & $\mathbb{R}^{+}$ & Gamma & 1.00 & 0.50 \\
\hline$\psi_{1}$ & $\mathbb{R}^{+}$ & Gamma & 1.50 & 0.25 \\
\hline$\psi_{2}$ & $\mathbb{R}^{+}$ & Gamma & 0.50 & 0.25 \\
\hline$\psi_{3}$ & $\mathbb{R}^{+}$ & Gamma & 0.10 & 0.05 \\
\hline$\psi_{1}^{*}$ & $\mathbb{R}^{+}$ & Gamma & 1.50 & 0.25 \\
\hline$\psi_{2}^{*}$ & $\mathbb{R}^{+}$ & Gamma & 0.50 & 0.25 \\
\hline$\psi_{3}^{*}$ & $\mathbb{R}^{+}$ & Gamma & 0.10 & 0.05 \\
\hline$\rho_{A}$ & {$[0,1)$} & Beta & 0.80 & 0.10 \\
\hline$\rho_{R}$ & {$[0,1)$} & Beta & 0.50 & 0.20 \\
\hline$\rho_{\mathrm{G}}$ & {$[0,1)$} & Beta & 0.80 & 0.10 \\
\hline$\rho_{A}^{*}$ & $(0,1)$ & Beta & 0.60 & 0.20 \\
\hline$\rho_{R}^{*}$ & {$[0,1)$} & Beta & 0.50 & 0.20 \\
\hline$\rho_{\mathrm{G}}^{*}$ & {$[0,1)$} & Beta & 0.80 & 0.10 \\
\hline$\rho_{\mathrm{Z}}$ & {$[0,1)$} & Beta & 0.66 & 0.15 \\
\hline$r^{(A)}$ & $\mathbb{R}^{+}$ & Gamma & 0.50 & 0.50 \\
\hline$\gamma$ & $\mathbb{R}$ & Normal & 0.40 & 0.20 \\
\hline$\pi^{(A)}$ & $\mathbb{R}^{+}$ & Gamma & 7.00 & 2.00 \\
\hline$\sigma_{A}$ & $\mathbb{R}^{+}$ & Inverse gamma & 1.00 & 4.00 \\
\hline$\sigma_{\mathrm{G}}$ & $\mathbb{R}^{+}$ & Inverse gamma & 1.00 & 4.00 \\
\hline$\sigma_{R}$ & $\mathbb{R}^{+}$ & Inverse gamma & 0.40 & 4.00 \\
\hline$\sigma_{A^{*}}$ & $\mathbb{R}^{+}$ & Inverse gamma & 0.40 & 4.00 \\
\hline$\sigma_{\mathrm{G}}$ & $\mathbb{R}^{+}$ & Inverse gamma & 1.00 & 4.00 \\
\hline$\sigma_{R^{*}}$ & $\mathbb{R}^{+}$ & Inverse gamma & 0.20 & 4.00 \\
\hline$\sigma_{Z}$ & $\mathbb{R}^{+}$ & Inverse gamma & 0.50 & 4.00 \\
\hline$\sigma_{E}$ & $\mathbb{R}^{+}$ & Inverse gamma & 3.50 & 4.00 \\
\hline
\end{tabular}

Notes: The prior is truncated at the boundary of the determinacy region. Para (1) and Para (2) list the means and the standard deviations for beta, gamma, and normal distributions; the upper and lower bound of the support for the uniform distribution; $s$ and $v$ for the inverse gamma distribution, where $p_{\mathscr{G}}(\sigma \mid v, s) \propto \sigma^{-v-1} e^{-r s^{2} / 2 \sigma^{2}}$. 
where:

$\tilde{A}_{t}=\rho_{A} \tilde{A}_{t-1}+u_{A, t} \quad \tilde{A}_{t}^{*}=\rho_{A} \cdot \tilde{A}_{t-1}^{*}+u_{A^{*}, t} \quad \tilde{z}_{t}=\rho_{z} \tilde{z}_{t-1}+u_{z, t}$

The estimate of $\gamma$ is used to set the prior mean for $\gamma$ in the analysis of the DSGE model. We use the estimates of $\rho_{z}$ and $\sigma\left(u_{z, t}\right)$ to inform the choice of prior means for the nonstationary technology process in the DSGE model. The processes $\tilde{A}_{t}$ and $\tilde{A}_{t}^{*}$ are not directly comparable to the country-specific technology processes in the DSGE model. Nevertheless, we use the estimates to guide the choice of prior for the remaining exogenous processes in the DSGE model. In order to obtain a prior for the standard deviation of the monetary policy shock, we estimate the following regression by OLS (for the United States and the Euro area):

$R_{t}=\beta_{0}+\beta_{1} R_{t-1}+\beta_{2} \pi_{t-1}+\beta_{2} \Delta Y_{t-1}+u_{R, t}$

The benchmark prior for $\sigma_{E}$, the standard deviation of the PPP shock, is based on the unconditional standard deviation of the nominal depreciation rate during the presample period. We vary this prior in our empirical analysis to assess how the fit of the model changes as a function of prior beliefs about the misspecification of the exchange rate equations.

The priors for the price stickiness parameters $\theta$ are chosen based on evidence on the average frequency of price changes. Following Bils and Klenow (2004), an average 26 percent of U.S. sectoral prices are changed every 3.3 months, which translates into a Calvo-adjustment parameter of $\theta_{H}=0.5$. Stickiness of import prices is set at the same level. For Euro area data, we use information reported by Angeloni et al. (2004) to set the prior mean at 0.75 . The prior mean for the intratemporal substitution elasticity $\eta$ is set at 1 , with a large standard deviation to account for uncertainty about its location. The priors for the coefficients in the monetary policy rule are loosely centered around values typically associated with the Taylor rule. We allow for the possibility of a small policy response to exchange rate movements in both countries, following Lubik and Schorfheide (2006). As a final point, it is well known that linear rational expectations models can have multiple equilibria. While this may be an issue of independent interest (see Lubik and Schorfheide 2004), we do not pursue this direction in this paper. The prior distribution for the model is therefore truncated at the boundary of the determinacy region. 


\section{Empirical Analysis}

The empirical analysis has three parts. We begin by estimating the two-country model developed in Section 3 under a benchmark prior distribution. We then document the sensitivity of the parameter estimates to changes in the prior. The second part studies the dynamics of the estimated NOEM model through impulse response functions. We assess the estimates of the transmission of monetary policy shocks under the benchmark prior and a perfect pass-through version of the model. Finally, we examine the estimated exchange rate dynamics and the relative importance of the various structural shocks for exchange rate fluctuations.

\subsection{Estimation}

Markov Chain Monte Carlo methods, described in Section 8.2 of the appendix, are used to generate draws from the posterior distribution of the model parameters. Based on these draws, we compute the summary statistics (posterior means and 90 percent probability intervals) reported in tables 5.2 to 5.7. The results in Sections 6.2 and 6.3 are obtained by converting the parameter draws into impulse response functions and variance decompositions. The estimated steady-state inflation rates, reported subsequently and denoted by $\pi^{(A)}$, are annualized. We also report a $r^{(A)}$, which is related to $\beta$ according to $\beta=$ $1 /\left(1+r^{(A)} / 400\right)$. Moreover, $\gamma$ is the quarter-to-quarter percentage growth rate of $A_{W, t}$.

6.1.1 Closed Versus Open Economy Estimates We begin our empirical analysis with a comparison of parameter estimates obtained from a closed and an open economy specification. If agents do not value goods produced abroad $(\alpha=0)$ and the exchange of financial assets across country borders is prohibited, our model reduces to the familiar New Keynesian closed economy (CE) DSGE model. Although Bayesian estimates for the $C E$ version have been reported elsewhere in the literature, we re-estimate CE models based on our particular model specification and data set. ${ }^{16}$ The results obtained under the benchmark prior distribution (table 5.1) are summarized in table 5.2. For convenience, we also reproduce prior means and probability intervals.

The closed economy U.S. estimates are, by and large, similar to the Euro area estimates. This finding is consistent with the results obtained 
Table 5.2

Open and Closed Economy Estimates

\begin{tabular}{|c|c|c|c|c|c|c|c|c|}
\hline & & & Poster & ior Distributio & & & & \\
\hline & Prior & & $\begin{array}{l}\text { United } \\
\text { Area }\end{array}$ & States-Euro & United & States & & \\
\hline & Mean & $90 \%$ Interval & Mean & $90 \%$ Interval & Mean & $90 \%$ Interval & Euro & Area \\
\hline$\theta_{H}$ & 0.50 & {$[0.25,0.75]$} & 0.66 & {$[0.53,0.80]$} & 0.65 & {$[0.51,0.82]$} & & \\
\hline$\theta_{F}$ & 0.50 & {$[0.25,0.74]$} & 0.56 & {$[0.28,0.86]$} & & & & \\
\hline$\theta_{H}^{*}$ & 0.75 & {$[0.53,0.98]$} & 0.86 & {$[0.73,1.00]$} & & & & \\
\hline$\theta_{F}^{*}$ & 0.75 & {$[0.53,0.98]$} & 0.76 & {$[0.67,0.85]$} & & & 0.64 & {$[0.47,0.85]$} \\
\hline$\tau$ & 2.00 & {$[1.19,2.79]$} & 3.76 & {$[2.81,4.69]$} & 2.77 & {$[1.91,3.61]$} & 3.01 & {$[2.12,3.87]$} \\
\hline$h$ & 0.30 & {$[0.14,0.46]$} & 0.41 & {$[0.15,0.67]$} & 0.40 & {$[0.19,0.62]$} & 0.48 & {$[0.27,0.70]$} \\
\hline$\alpha$ & 0.12 & {$[0.04,0.20]$} & 0.13 & {$[0.04,0.23]$} & & & & \\
\hline$\eta$ & 1.00 & {$[0.23,1.73]$} & 0.43 & {$[0.07,0.80]$} & & & & \\
\hline$\psi_{1}$ & 1.50 & {$[1.09,1.89]$} & 1.41 & {$[1.03,1.75]$} & 1.51 & {$[1.07,1.89]$} & & \\
\hline$\psi_{2}$ & 0.50 & {$[0.12,0.87]$} & 0.66 & {$[0.38,0.96]$} & 0.69 & {$[0.37,1.00]$} & & \\
\hline$\psi_{3}$ & 0.10 & {$[0.02,0.17]$} & 0.03 & {$[0.01,0.05]$} & & & & \\
\hline$\psi_{1}^{*}$ & 1.50 & {$[1.09,1.89]$} & 1.37 & {$[1.08,1.65]$} & & & 1.80 & {$[1.42,2.17]$} \\
\hline$\psi_{2}^{*}$ & 0.50 & {$[0.13,0.88]$} & 1.27 & {$[0.80,1.73]$} & & & 0.49 & {$[0.20,0.78]$} \\
\hline$\psi_{3}^{*}$ & 0.10 & {$[0.02,0.17]$} & 0.03 & {$[0.01,0.05]$} & & & & \\
\hline$\rho_{A}$ & 0.80 & {$[0.65,0.96]$} & 0.83 & {$[0.75,0.92]$} & 0.85 & {$[0.78,0.93]$} & & \\
\hline$\rho_{\mathrm{R}}$ & 0.50 & {$[0.18,0.84]$} & 0.76 & {$[0.70,0.81]$} & 0.76 & {$[0.71,0.82]$} & & \\
\hline$\rho_{G}$ & 0.80 & {$[0.65,0.96]$} & 0.90 & {$[0.83,0.97]$} & 0.88 & {$[0.80,0.97]$} & & \\
\hline$\rho_{A}^{*}$ & 0.60 & {$[0.29,0.93]$} & 0.85 & {$[0.77,0.94]$} & & & 0.89 & {$[0.85,0.94]$} \\
\hline$\rho_{R}^{*}$ & 0.50 & {$[0.18,0.83]$} & 0.84 & {$[0.80,0.88]$} & & & 0.83 & {$[0.77,0.89]$} \\
\hline$\rho_{G}^{*}$ & 0.80 & {$[0.65,0.96]$} & 0.94 & {$[0.91,0.97]$} & & & 0.88 & {$[0.78,0.97]$} \\
\hline$\rho_{Z}$ & 0.66 & {$[0.42,0.91]$} & 0.60 & {$[0.40,0.82]$} & 0.64 & {$[0.45,0.85]$} & 0.54 & {$[0.33,0.75]$} \\
\hline$r^{(A)}$ & 0.50 & {$[0.00,1.15]$} & 0.86 & {$[0.29,1.40]$} & 0.45 & {$[0.00,0.86]$} & 1.68 & {$[0.81,2.54]$} \\
\hline$\gamma$ & 0.40 & {$[0.07,0.73]$} & 0.39 & {$[0.23,0.55]$} & 0.43 & {$[0.25,0.60]$} & 0.42 & {$[0.26,0.58]$} \\
\hline$\pi^{(A)}$ & 7.00 & {$[3.72,10.11]$} & 3.16 & {$[2.50,3.83]$} & 3.30 & {$[2.50,4.01]$} & 2.92 & {$[2.18,3.64]$} \\
\hline$\sigma_{A}$ & 1.26 & {$[0.53,1.99]$} & 1.66 & {$[0.89,2.44]$} & 1.53 & {$[0.81,2.13]$} & & \\
\hline$\sigma_{G}$ & 1.26 & {$[0.53,1.98]$} & 0.50 & {$[0.41,0.58]$} & 0.47 & {$[0.39,0.56]$} & & \\
\hline$\sigma_{R}$ & 0.50 & {$[0.21,0.79]$} & 0.18 & {$[0.15,0.21]$} & 0.18 & {$[0.15,0.21]$} & & \\
\hline$\sigma_{A^{*}}$ & 0.50 & {$[0.21,0.79]$} & 2.61 & {$[1.18,4.16]$} & & & 1.89 & {$[0.94,2.87]$} \\
\hline$\sigma_{G}$ & 1.25 & {$[0.52,1.97]$} & 0.62 & {$[0.50,0.73]$} & & & 0.49 & {$[0.40,0.57]$} \\
\hline$\sigma_{R}=$ & 0.25 & {$[0.11,0.40]$} & 0.18 & {$[0.14,0.21]$} & & & 0.15 & {$[0.12,0.18]$} \\
\hline$\sigma_{Z}$ & 0.63 & {$[0.27,0.99]$} & 0.35 & {$[0.23,0.47]$} & 0.37 & {$[0.24,0.49]$} & 0.40 & {$[0.26,0.54]$} \\
\hline$\sigma_{E}$ & 4.39 & {$[1.82,6.90]$} & 4.48 & {$[3.88,5.07]$} & & & & \\
\hline
\end{tabular}


by Rabanal and Rubio-Ramírez $(2003,2005)$ and Smets and Wouters (2004). There is a substantial overlap of the confidence sets for $\tau, h, \rho_{z}$, $\gamma, \pi^{(A)}$, and $\sigma_{z}$, supporting the symmetry assumptions built into the two-country model. Only the estimates of $r^{(A)}$ differ. In our model, $r^{(A)}+4 \gamma$ determines the steady-state real interest rate. According to the closed economy estimates, the real interest rate in the Euro area was more than 100 basis points higher than in the United States over the sample period. The Calvo parameters $\theta_{H}$ and $\theta_{F}^{*}$ are about 0.65 , implying an average duration between price optimizations of three quarters. The 90 percent probability intervals range from about 0.5 to 0.85 . These numbers are comparable to estimates reported elsewhere in the literature: Rabanal and Rubio-Ramirez $(2003,2005)$ obtain 0.77 for the United States (sample period 1960-2001) and 0.82 for the Euro area (sample period 1970-2003). Galí and Rabanal (2004) estimate $\theta_{H}$ to be 0.53 in a slightly larger model (sample period 1948-2002), and Schorfheide (2005) reports 0.55 (sample period 1960-1997). On the demand side, habit formation seems to play an important role in both the United States and the Euro area. The estimates of $h$ are 0.40 and 0.48 , respectively. The policy rule estimates imply fairly strong responses to inflation and output growth movements by both the U.S. Federal Reserve as well as the European monetary authority.

The open economy estimates are, by and large, similar to the closed economy estimates, with a few exceptions. The posterior mean of the nominal rigidity in the Euro area production sector rises from 0.64 to 0.76 , a value that is not unreasonable given the estimates reported elsewhere and the probability intervals from the $\mathrm{CE}$ estimation. The posterior mean of the risk aversion parameter $\tau$ increases from 2.8 and 3.0, respectively, to about 3.8 . While the policy rule coefficients for the United States are not affected by the inclusion of the Euro area data, $\hat{\psi}_{1}^{*}$ drops from 1.80 to 1.37 and $\hat{\psi}_{2}^{*}$ increases from 0.49 to 1.27 . There are two potential sources for this discrepancy: first, the two-country model imposes common steady states for the United States and the Euro area, which implies that the estimated fluctuations around the steady states have potentially changed. Notice that $\hat{r}^{(A)}$ is 0.86 in the open economy specification but rises to 1.68 if the closed economy model is fitted to Euro area data. Second, the likelihood function associated with the two-country model might generate a different correction for the endogeneity of the regressors included in the policy rule equation (see Section 4). We will investigate this issue below by estimating the models with detrended data. We included the depreciation 
rate as an argument into the policy rule but found that the corresponding coefficient estimates for the United States and the Euro area are nearly 0 . This finding complements the empirical results reported in Lubik and Schorfheide (2006), who find no evidence of exchange rate responses for a variety of small open economies.

The prior distribution for the import share parameter $\alpha$ and the nominal rigidity in the U.S. import sector $\theta_{F}$ are essentially not updated, indicating that the likelihood function is not informative with respect to these parameters. The estimated substitution elasticity between home and foreign goods, $\eta$, is 0.4 , a number that is substantially lower than the values that are typically used in calibration studies. This finding is robust to all specifications we investigated. It suggests that home and foreign output are not very responsive to movements in terms of trade differentials, which in turn are related to the l.o.p. gaps. Consequently, imperfect pass-through does not seem to play an important role in driving output.

Finally, our estimated standard deviation of the PPP shock is large, suggesting that the model is unable to generate the real exchange rate fluctuations that we observe in the data. Since the importance of shocks cannot directly be assessed from the magnitude of the associated standard deviation due to normalization issues, we decompose the variance of exchange rate fluctuations in Section 6.3 .

6.1.2 Estimation Based on Demeaned Data So far, we imposed all the long-run restrictions implied by our open economy model, in particular, a common technology growth rate $\gamma$, a common steady-state inflation rate $\pi^{(A)}$, and a common steady-state real interest rate $r^{(A)}+4 \gamma$. Many of the key equations in an open economy model, such as uncovered interest rate parity or purchasing power parity, have to hold in levels and not just in terms of deviations from steady state. Persistent deviations from these steady-state relationships in the data are typically absorbed in the estimated exogenous shock processes and might lead to a contamination of the parameter estimates. In order to assess the effect of the imposed long-run restrictions on the parameter estimation, we re-estimate the open and closed economy specifications based on demeaned data. The results for some of the key parameters are reported in table 5.3. For most of the parameter estimates, the effect of demeaning the data is small. Not surprisingly, those open economy parameter estimates that do shift are now more similar to their closed economy counterparts. Examples are $\hat{\theta}_{F}^{*}, \hat{\psi}_{1}^{*}$, and $\hat{\psi}_{2}^{*}$. 
Table 5.3

Open and Closed Economy Estimates-Demeaned Data

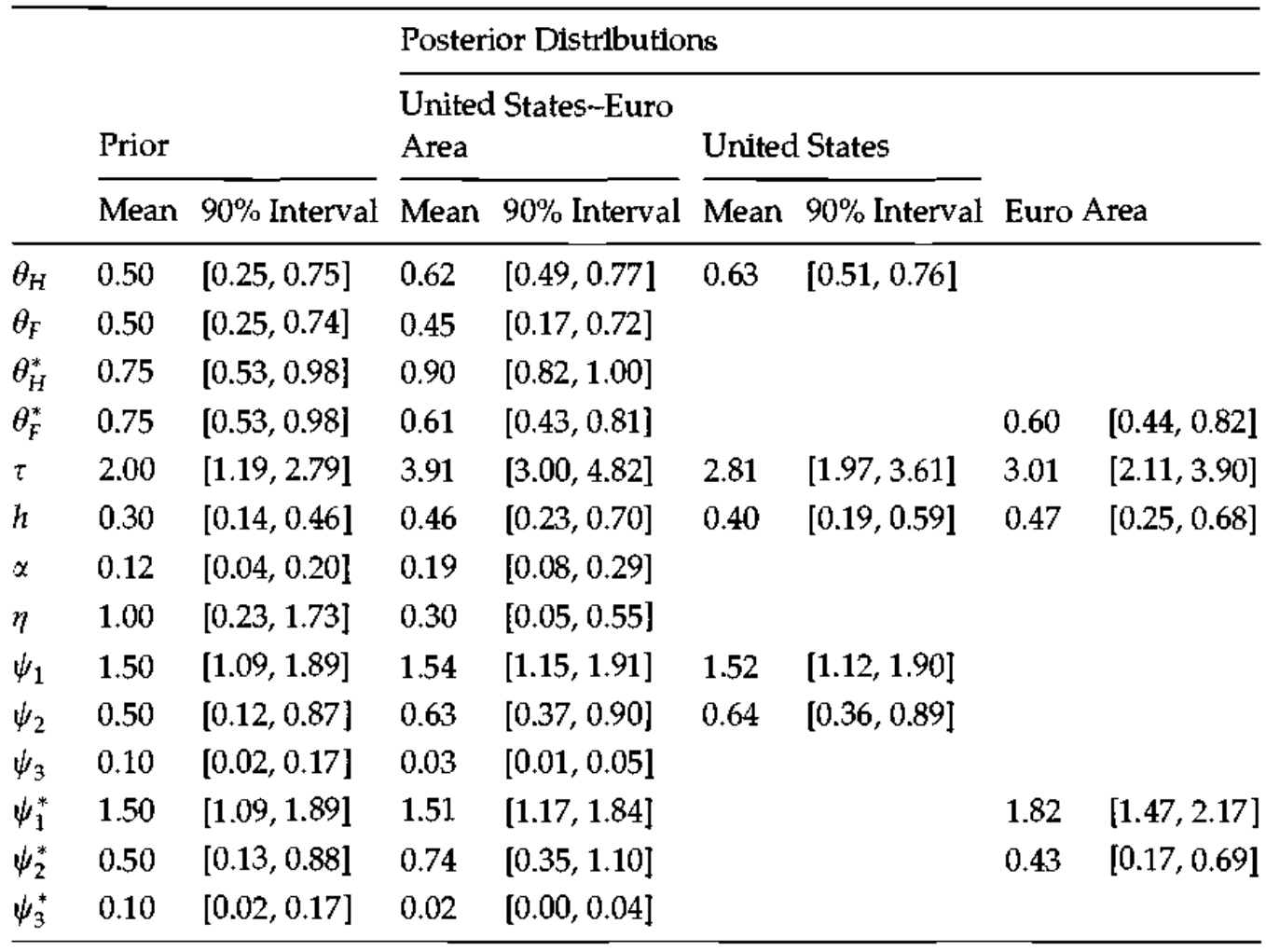

6.1.3 Estimation Under Alternative Priors In order to assess the sensitivity of our parameter estimates to the choice of prior distribution, we re-estimate the open economy model under several alternative prior distributions. The modifications of the prior distribution are presented in table 5.4, and the corresponding posteriors for key parameters are summarized in table 5.5. Since our previous analysis indicated that the monetary authorities in the United States and the Euro area do not respond to exchange rate movements, we impose $\psi_{3}=\psi_{3}^{*}=0$ and also re-estimate the model under the (modified) benchmark prior.

First, we consider a perfect pass-through version of our model, that is, $\theta_{F}=\theta_{H}^{*}=0$. It turns out that the model without nominal rigidities in the import section roughly leads to similar parameter estimates as the benchmark model. Without data on import prices, it is very difficult to measure the degree of price stickiness in the import sector. We will revisit this point when we examine the impulse response dynamics of the estimated models.

Diffuse prior I replaces the beta-priors for the Calvo parameters by uniform distributions. Moreover, we make the priors for the autocorrelations of the exogenous processes less informative by changing them 
Table 5.4

Alternative Prior Distributions

\begin{tabular}{lllll}
\hline Name & Domain & Density & Para (1) & Para (2) \\
\hline Perfect pass-through & & & \\
$\theta_{F}$ & {$[0,1)$} & Fixed & 0.00 & \\
$\theta_{H}^{*}$ & {$[0,1)$} & Fixed & 0.00 & \\
Diffuse prior I & & & & \\
$\theta_{H}$ & {$[0,1)$} & Uniform & 0.00 & 1.00 \\
$\theta_{F}$ & {$[0,1)$} & Uniform & 0.00 & 1.00 \\
$\theta_{H}^{*}$ & {$[0,1)$} & Uniform & 0.00 & 1.00 \\
$\theta_{F}^{*}$ & {$[0,1)$} & Uniform & 0.00 & 1.00 \\
$\rho_{A}$ & {$[0,1)$} & Uniform & 0.00 & 1.00 \\
$\rho_{R}$ & {$[0,1)$} & Uniform & 0.00 & 1.00 \\
$\rho_{G}$ & {$[0,1)$} & Uniform & 0.00 & 1.00 \\
$\rho_{A}^{*}$ & {$[0,1)$} & Uniform & 0.00 & 1.00 \\
$\rho_{R}^{*}$ & {$[0,1)$} & Uniform & 0.00 & 1.00 \\
$\rho_{G}^{*}$ & {$[0,1)$} & Uniform & 0.00 & 1.00 \\
Diffuse prior $I I$ & & & & \\
$\tau$ & $\mathbb{R}^{+}$ & Gamma & 2.00 & 2.00 \\
$h$ & {$[0,1)$} & Uniform & 0.00 & 1.00 \\
$\alpha$ & {$[0,1)$} & Uniform & 0.00 & 1.00 \\
$\eta$ & $\mathbb{R}^{+}$ & Gamma & 1.00 & 1.00 \\
\hline
\end{tabular}

Notes: Para (1) and Para (2) list the means and the standard deviations for beta, gamma, and normal distributions; the upper and lower bound of the support for the uniform distribution.

to uniform distributions as well. Diffuse prior II relaxes some of the restrictions that we placed on the preference parameters. We find the benchmark posteriors to be sensitive to changes in the prior distribution. For instance, the posterior mean of $\alpha$ rises from 0.16 to 0.39 (diffuse prior I) and 0.74 (diffuse prior II), respectively. Since we are not using direct observations on the magnitude of bilateral trade between the United States and the Euro area, the estimate of $\alpha$, in particular under diffuse prior II, becomes counterfactually large, while the intratemporal substitution elasticity $\eta$ declines considerably to compensate for the change in $\alpha$. The estimate of $\eta$ is not anchored by direct observation of sectoral prices and quantities.

If we relax the priors on the Calvo parameters, $\hat{\theta}_{H}^{*}$ is essentially 1 and $\hat{\theta}_{F}^{*}$ drops from 0.71 to 0.17 . Information on price stickiness in the United States and in the Euro area is obtained from the CPI inflation series. According to the model, CPI inflation is a function of inflation 
Table 5.5

Posterior Estimates Under Alternative Priors

\begin{tabular}{|c|c|c|c|c|c|c|c|c|}
\hline & \multicolumn{2}{|c|}{ Benchmark } & \multicolumn{2}{|c|}{$\begin{array}{l}\text { Perfect Pass- } \\
\text { Through }\end{array}$} & \multicolumn{2}{|c|}{ Diffuse Prior I } & \multicolumn{2}{|c|}{ Diffuse Prior Il } \\
\hline & Mean & $90 \%$ Interval & Mean & $90 \%$ Interval & Mean & $90 \%$ Interval & Mean & $90 \%$ Interval \\
\hline$\theta_{H}$ & 0.66 & {$[0.52,0.83]$} & 0.60 & {$[0.43,0.77]$} & 0.43 & {$[0.22,0.68]$} & 0.53 & {$[0.40,0.67]$} \\
\hline$\theta_{F}$ & 0.50 & {$[0.21,0.78]$} & 0.00 & {$[0.00,0.00]$} & 0.09 & {$[0.00,0.20]$} & 0.66 & {$[0.41,0.89]$} \\
\hline$\theta_{H}^{*}$ & 0.86 & {$[0.73,1.00]$} & 0.00 & {$[0.00,0.00]$} & 0.99 & {$[0.99,1.00]$} & 0.91 & {$[0.86,0.95]$} \\
\hline$\theta_{F}^{*}$ & 0.74 & {$[0.60,0.85]$} & 0.77 & {$[0.68,0.86]$} & 0.17 & {$[0.00,0.41]$} & 0.32 & {$[0.13,0.51]$} \\
\hline$\tau$ & 3.61 & {$[2.72,4.49]$} & 3.84 & {$[2.82,4.79]$} & 3.53 & {$[2.57,4.52]$} & 6.45 & {$[3.72,9.61]$} \\
\hline$h$ & 0.41 & {$[0.14,0.66]$} & 0.47 & {$[0.23,0.71]$} & 0.63 & {$[0.44,0.82]$} & 0.84 & {$[0.64,0.99]$} \\
\hline$\alpha$ & 0.14 & {$[0.05,0.24]$} & 0.07 & {$[0.03,0.10]$} & 0.39 & {$[0.21,0.53]$} & 0.74 & {$[0.51,0.88]$} \\
\hline$\eta$ & 0.43 & {$[0.05,0.82]$} & 0.35 & {$[0.06,0.67]$} & 0.18 & {$[0.04,0.30]$} & 0.18 & {$[0.00,0.29]$} \\
\hline$\psi_{1}$ & 1.43 & {$[1.06,1.76]$} & 1.54 & {$[1.17,1.90]$} & 1.79 & {$[1.42,2.16]$} & 1.82 & {$[1.45,2.21]$} \\
\hline$\psi_{2}$ & 0.63 & {$[0.34,0.92]$} & 0.57 & {$[0.31,0.82]$} & 0.38 & {$[0.16,0.59]$} & 0.40 & {$[0.18,0.62]$} \\
\hline$\psi_{3}$ & 0.00 & {$[0.00,0.00]$} & 0.00 & {$[0.00,0.00]$} & 0.00 & {$[0.00,0.00]$} & 0.00 & {$[0.00,0.00]$} \\
\hline$\psi_{1}^{*}$ & 1.37 & {$[1.06,1.66]$} & 1.39 & {$[1.09,1.67]$} & 1.85 & {$[1.52,2.19]$} & 1.61 & {$[1.25,1.96]$} \\
\hline$\psi_{2}^{*}$ & 1.13 & {$[0.67,1.57]$} & 1.03 & {$[0.61,1.44]$} & 0.49 & {$[0.20,0.75]$} & 0.57 & {$[0.26,0.86]$} \\
\hline$\psi_{3}^{*}$ & 0.00 & {$[0,00,0.00]$} & 0.00 & {$[0,00,0.00]$} & 0.00 & {$[0.00,0.00]$} & 0.00 & {$[0.00,0.00]$} \\
\hline
\end{tabular}

Note: We fixed $\psi_{3}=\psi_{3}^{*}=0$ in all specifications.

in the domestic production sector and the import sector. Without sample information on import prices, however, it is difficult to disentangle the sources of stickiness. The estimates suggest that under diffuse prior I, almost all the stickiness in the Euro area consumer prices is attributed to import price rigidity.

It is interesting to note that the posteriors of the policy rule coefficients are also affected by the choice of priors for the nonpolicy parameters, in particular for the Euro area. As discussed in Section 4, the estimation of policy rules involves a regression with endogenous regressors. The DSGE model is used to construct a conditional expectation of the monetary policy shock given the current values of the endogenous regressors (inflation and output growth). This conditional expectation is used to correct for the endogeneity. Changes in the prior distribution seem to generate different correction terms and hence lead to different parameter estimates.

Overall, we conclude that the prior distribution plays an important role in the system-based estimation for DSGE models. For instance, in the case of the import share coefficient $\alpha$ and the nominal rigidity parameters $\theta_{F}$ and $\theta_{H}^{*}$, the prior can be used to incorporate additional information that is not contained in the estimation sample $Y$. This 
information down-weighs the likelihood function in a region of the parameter space that is implausible in the light of data on the magnitude of bilateral trade and avoids a contamination of other parameter estimates.

In addition to the results reported in table 5.5, we carried out a number of additional robustness checks. The disturbance $\epsilon_{E, t}$ captures exogenous deviations from PPP that cannot be explained via the perfect pass-through mechanism. More generally, it captures model misspecification. We estimated the model subject to the restriction that $\sigma_{E}=0$ and under a number of prior distributions that shrink the estimate of $\sigma_{E}$ toward 0 . Whenever we restricted the variance of the PPP shock, the likelihood fit of the model deteriorated substantially, and the estimated standard deviation of at least one of the structural shocks increased dramatically to capture the nominal exchange rate fluctuations observed in the data.

In order to improve the fit of his two-country model, Bergin (2004) introduces a serially correlated shock to the UIP equation that increases the variability of the expected exchange rate depreciation $E_{t-1}\left[\Delta \tilde{e}_{t}\right]$. This reduces the volatility of the unexpected component $\Delta \tilde{e}_{t}-E_{t-1}\left[\Delta \tilde{e}_{t}\right]$ that has to be explained by the structural shocks of the model. In Bergin's setup, the UIP shock is correlated with the other structural shocks. We estimated a specification with an iid UIP shock and found that such a shock is unable to explain the observed exchange rate fluctuations. The fit of the UIP shock specification was very poor compared to the version of the model with PPP shock.

Finally, in the conference draft of this paper, we reported estimation results for a model in which the central banks react to deviations of output from the stochastic trend $A_{W, t}$, instead of deviations of output growth rates from the steady-state growth rate. Moreover, we did not impose a common steady-state inflation rate. The parameter estimates of the output gap version of the model were very sensitive to the underlying potential output series that was implicitly constructed through the latent exogenous processes. For instance, the estimated Calvo parameter for the U.S. production sector, $\hat{\theta}_{H}$, dropped from 0.78 in the closed economy specification to 0.46 in the open economy version. The posterior mean of the U.S. policy rule coefficient $\psi_{2}$ decreased from 0.56 to 0.01 by switching from a closed to an open economy setting.

6.1.4 Model Fit Table 5.6 reports log marginal data densities for the various specifications that we have estimated. The fit of the benchmark specification is improved by imposing that the central banks do not 
Table 5.6

Log Marginal Data Densities

\begin{tabular}{lr}
\hline DSGE model: benchmark prior, $\psi_{3}, \psi_{3}^{*}$ estlmated & -795.22 \\
DSGE model: benchmark prior, $\psi_{3}=\psi_{3}^{*}=0$ & -786.78 \\
DSGE model: perfect pass-through & -788.58 \\
DSGE model: diffuse prior I & -788.83 \\
DSGE model: diffuse Prior II & -763.66 \\
VAR(4): $\tau=2$ & -834.18 \\
VAR(4): $\tau=3$ & -788.93 \\
VAR(4): $\tau=5$ & -754.34 \\
VAR(4): $\tau=20$ & -795.19
\end{tabular}

Note: The log marginal data densities for the DSGE model specifications are computed based on Geweke's (1999) modified harmonic mean estimator. The marginal data densities for the VARs are calculated analytically (see section 8.3 in the appendix).

respond to exchange rate movements. The assumption of perfect passthrough leads to a slight deterioration of fit, and so does the diffuse prior I. It is important to note that the marginal data density penalizes the likelihood fit by a measure of model complexity. Making a prior distribution more diffuse is equivalent to the removal of restrictions on parameters and increases the model complexity (approximately measured by the log determinant of the posterior covariance matrix of the parameters). For diffuse prior II, the improvement in model fit dominates the penalty for increased model complexity and the marginal data density improves by 24 points on a $\log$ scale. This indicates that the benchmark prior restricts the parameter estimates from moving into an area of the parameter space that yields a higher likelihood. If one is willing to interpret the benchmark prior as driven by empirical evidence not contained in the estimation sample $Y$, then there seems to be a tension here. Trying to keep the estimates close to values that are consistent with this additional information, e.g., a small import share $\alpha$, leads to a deterioration of model fit.

We also report marginal data densities for reduced form vector autoregressions with four lags, estimated under various Minnesotatype prior distributions. Details on the VAR estimation are relegated to Section 8.3 of the appendix. The hyperparameter $\tau$ controls the tightness of the prior distribution. The larger is $\tau$, the more the parameter estimates are tilted toward the prior mean. The marginal data density of the VAR is quite sensitive to the choice of hyperparameter. For $\tau=3$, the fit of the Bayesian VAR and the DSGE model are roughly at 
par, whereas for $\tau=5$, the VAR clearly dominates all specifications of the DSGE model. While the two-country model seems to suffer from misspecified cross-coefficient restrictions, not every VAR dominates the DSGE model. Hence, careful attention has to be paid to model fit if the DSGE model is supposed to be evaluated based on VAR estimates. The loss-function-based evaluation framework of Schorfheide (2000) and the DSGE model prior approach of Del Negro and Schorfheide (2004) enable more refined comparisons between DSGE models and a VAR that account for model fit.

\subsection{Impulse Response Analysis}

We can develop some understanding of the inherent dynamics and the relative importance of different shocks by computing impulse response functions. The responses of endogenous variables of interest to onestandard-deviation structural shocks are reported in figure 5.2. We first discuss overall results for the benchmark model. We then focus on the effects of monetary policy shocks and the importance of imperfect pass-through.

The effects of monetary policy shocks are as expected (first and second row of the panel). Inflation and output declime in response to contractionary domestic policy. The inflation response in the United States is stronger than in the Euro area on account of a higher policy coefficient. Interest rate shocks sharply appreciate the currency, as depicted in the last column, but the effect quickly dissipates within a few periods. A monetary contraction in the United States leads to a rise in European output and inflation, to which the monetary authority responds endogenously with an interest rate hike. The transmission of European monetary shocks to the United States is weaker and estimated with less precision. The main transmission mechanism of shocks between countries in this model are relative price movements that are implied by and are consistent with perfect risk sharing. This has an expenditure switching effect away from domestic goods toward foreign output.

U.S. technology shocks are expansionary at home, and they lower prices and the interest rate, thereby depreciating the dollar. European technology shocks have similar effects on Euro area variables. Transmission of productivity disturbances is negative, however, lowering output. This can be explained by the assumption of perfect risksharing, which leads to production shifting to the country with the highest productivity. In contrast, government expenditure shocks have 
Percentage Deviations From Steady State
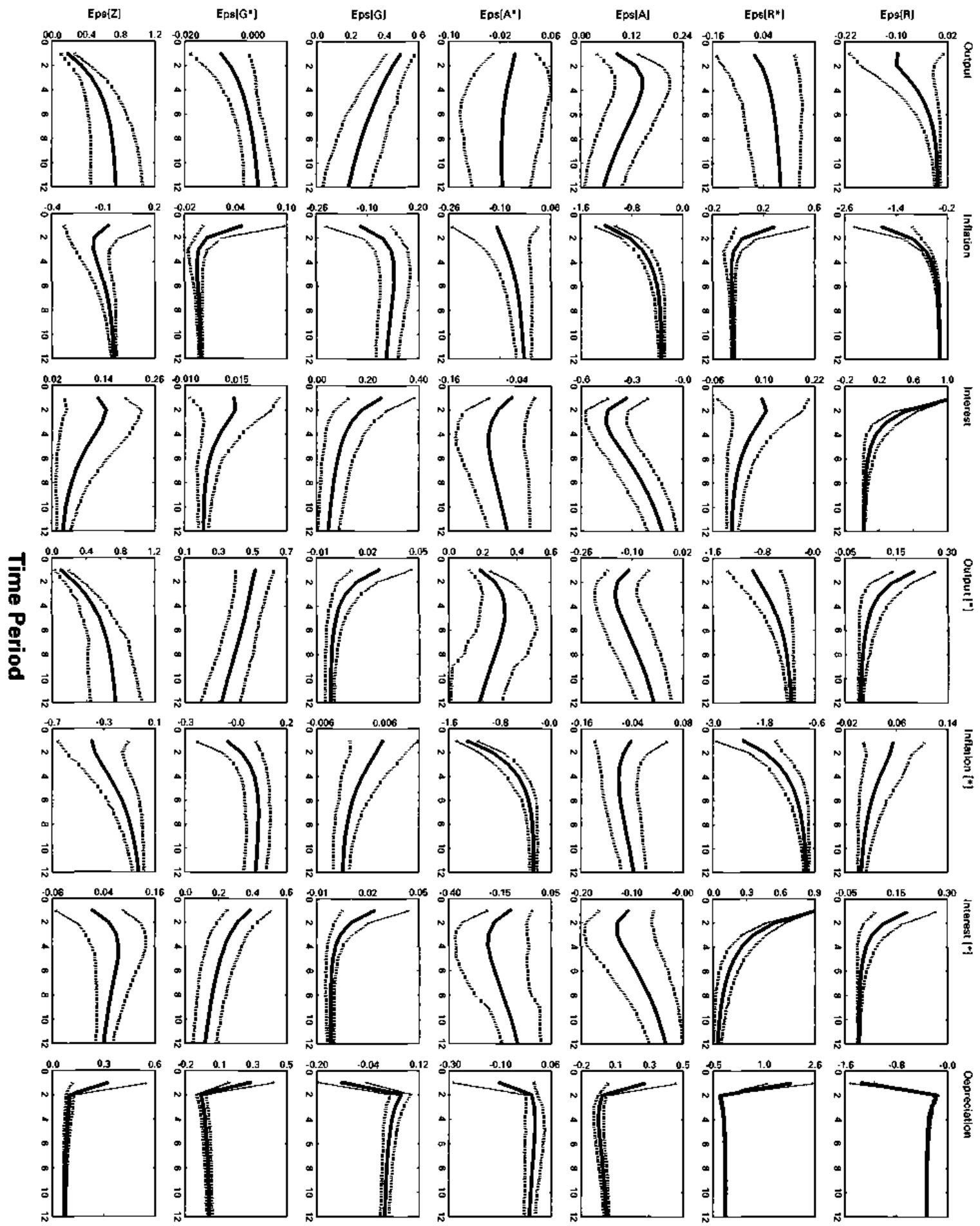

Figure 5.2

Impulse Response Functions for Benchmark Estimation

Note: Figure depicts posterior means (solid lines) and pointwise $90 \%$ posterior probability intervals (dashed lines) for impulse responses of endogenous variables to one standard deviation structural shocks. 
supply effects via relative price changes. The effects of government purchases are broadly similar in both economies. Output expands, inflation declines, the currency appreciates. Transmission from the United States to the Euro area is positive, while transmission in the other direction is negative.

In a perfectly symmetric model, worldwide productivity shocks would not have any effects on relative prices. In our framework, however, they imply a dollar depreciation (see the seventh row of the panel). Since the Euro interest rate barely responds, the positive differential in favor of the United States requires an expected depreciation. Together with the inflation differential in favor of the United States, this pattern explains the behavior of the exchange rate. Different degrees of price stickiness therefore play a role in determining the direction of exchange rate responses.

We look at this issue in more detail by considering impulse responses to expansionary U.S. monetary policy shocks in isolation. Figure 5.3 reports results for the benchinark prior and for the case of perfect pass-through. The responses are remarkably similar. The exception is the behavior of import inflation. Under imperfect pass-through, adjustment is smooth and gradual, driven by the l.o.p. gap and ultimately by differential terms of trade movements. Under perfect passthrough, import inflation essentially reflects the nominal exchange rate.

This is not to say that this particular mechanism of introducing deviations from PPP is conceptually flawed or important. But it highlights the difficulties of explaining disaggregated behavior with aggregate data alone. This outcome is likely to be changed when sectoral inflation rates, more specifically, import price inflation data, are used because this would allow us to explain their behavior directly.

\subsection{What Determines Exchange Rate Dynamics?}

Our estimation methodology allows us to decompose exchange rate volatility into individual components explained by the disturbances in the model. The model is driven by seven structural shocks (monetary policy, technology, and government purchases) to which we add an additional disturbance in the form of an error term appended to the equation defining the nominal depreciation rate. The disturbance is not strictly structural because it is not contained in the model's primitives. It captures deviations from PPP not already explained endogenously through imperfect pass-through. However, this interpretation is problematic since it is not tied to behavior by the agents in the model. 

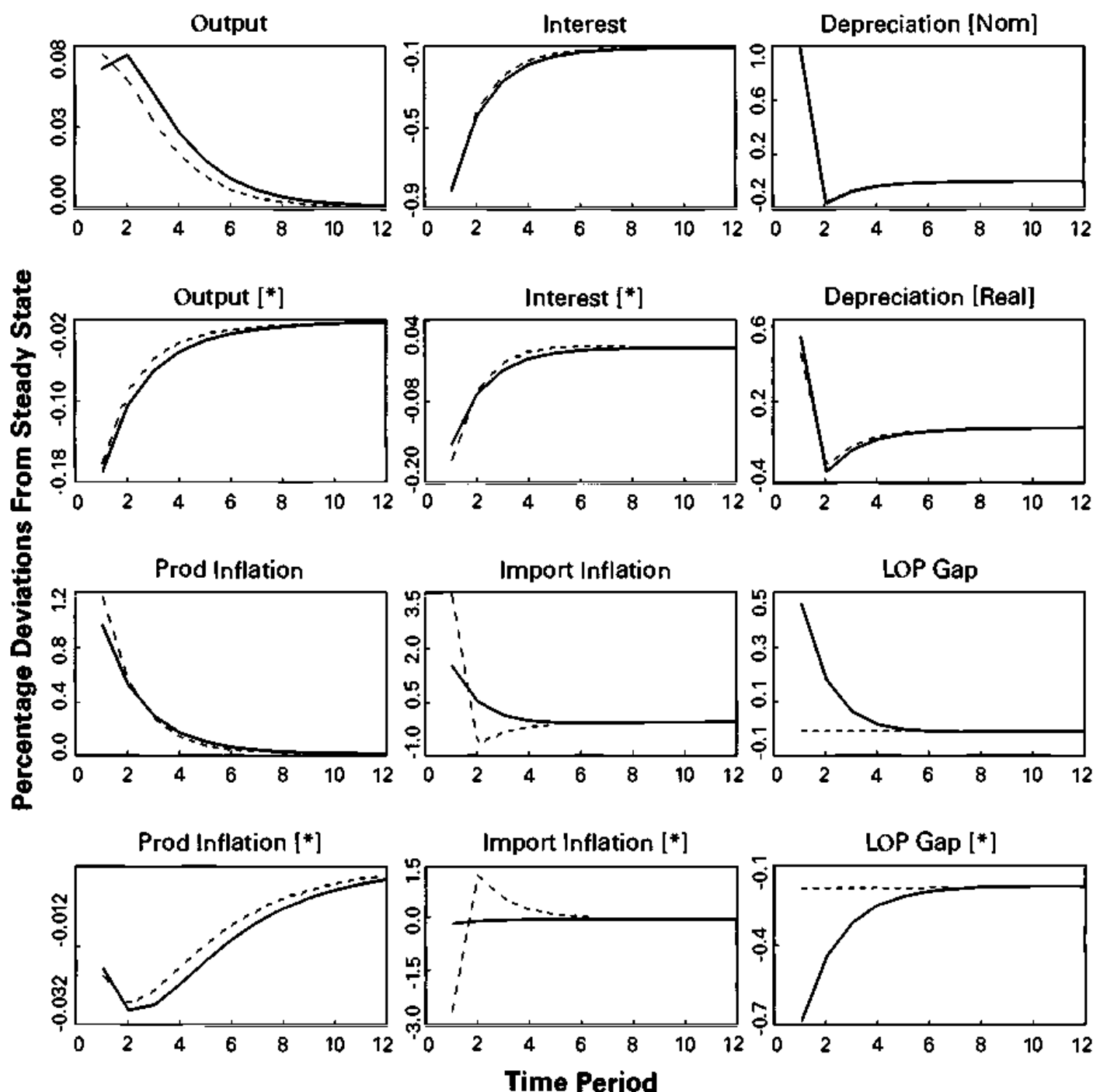

Figure 5.3

Impulse Responses to a U.S. Monetary Policy Shock

Note: Figure depicts impulse response functions at posterior mean parameter estimates (reported in table 5.5). Solid-line responses correspond to imperfect pass-through, dashedline responses correspond to perfect pass-through, which were obtained by setting $\theta_{F}=$ $\theta_{H}^{*}=0$.

Nevertheless, it is often instructive to add disturbances of this type because they provide a measure of the extent that the data are explained by specific features of the model. In a purely econometric sense, introducing these shocks allows a better fit of individual equations since they do not appear anywhere else in the model and do not have to obey any cross-equation restrictions. Without these shocks, the estimation procedure attempts to fit the model's unobservables base on a tightly restricted equation, such as the definition of the depreciation rate, which may result in implausible estimates. 
We report variance decompositions for the depreciation rate in table 5.7. Notice that the prior distribution on $\theta$ induces a prior distribution for the variance decomposition of the exchange rate fluctuations. We consider two priors: the benchmark prior with the exchange rate coefficient set to 0 , and a prior that imposes full pass-through. Under both priors, the PPP shock explains about 80 percent of exchange rate fluctuations, while monetary policy shocks make the biggest model-based contribution. It turns out that the data are very informative with respect to the variance decompositions, and the posteriors obtained under these priors look very similar.

In our benchmark estimation, PPP shocks explain 93 percent of the variability of the depreciation rate. This result had already been hinted at by the estimated variance of the PPP shock, which is an order of magnitude larger than those of other disturbances. The second largest component is the Euro area monetary policy shock, followed by the U.S. policy shock. By and large, the contribution of real shocks is almost negligible. The same conclusion emerges from the estimation under perfect pass-through, which attributes a slightly larger percentage of exchange rate movements to the PPP shock.

Overall, these results do not lend support to the notion that exchange rate dynamics are largely driven by real shocks, at least as far the endogenous components are concerned. Our benchmark model can thus explain roughly 10 percent of the movements in the depreciation rate. This result is not immediately comparable to other contributions in the literature mainly because of different methodologies applied. Calibration studies typically study only one shock at a time and attempt to match a small set of statistics with large degrees of freedom in setting parameters.

Methodologically comparable results can be found in Bergin (2004). He reports that monetary policy shocks contribute between 50 percent and 70 percent to exchange rate movements at longer horizons. His approach differs from ours in various ways, however. Bergin introduces UIP shocks that are correlated with the structural shocks in the model. He shows that different orthogonalization schemes change the variance decompositions considerably. It is therefore not a priori clear whether the influence attributed to monetary policy shocks is the artifact of an orthogonalization scheme. Using long-run identification restrictions in a VAR framework, Ahmed, Ickes, Wang, and Yoo (1993) do not find support for a role for monetary policy shocks in exchange rate dynamics. On the other hand, in a VAR study using 


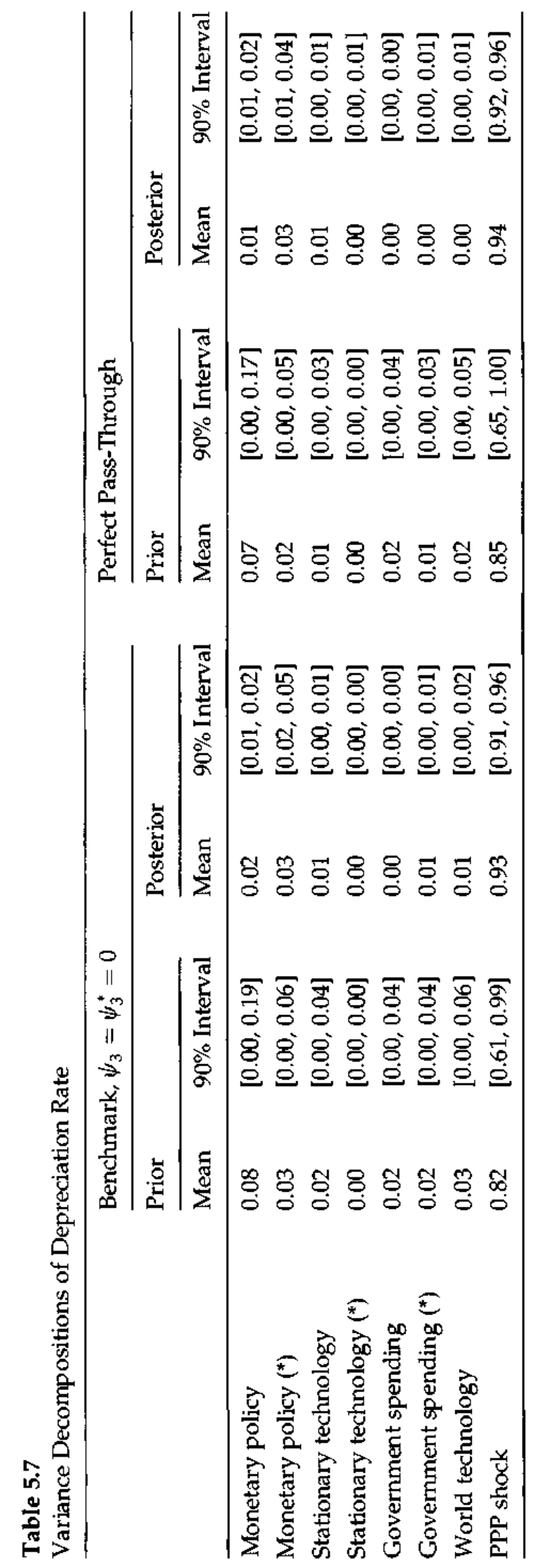


similar identification, Clarida and Galí (1994) show that monetary shocks, demand shocks in their interpretation, are a main driving force behind output movements over short horizons. This suggests that the lack of explanatory power derives from the disconnect between output movements and relative prices that is also evident in our model. ${ }^{17}$

The variance decompositions are not robust, however, to seemingly minor changes in the model specification. In the conference draft of this paper, we reported results from a specification that used the level of output relative to technology $A_{W, t}$ as the target variable in the policy rule. This specification attributed 20 percent of exchange rate movements to the structural shocks. Estimates with diffuse priors showed that the endogenous component to exchange rate movements can even be increased to beyond 20 percent when more endogenous persistence is allowed via habit formation, for instance. Moreover, monetary policy shocks did not have any significant influence at all because the exchange rate was largely driven by Euro area technology and government shocks. A possible explanation for this finding is that these real shocks operate mostly in fact through the monetary policy rules by creating movements in the model implied output gap that affect the exchange rates.

The conclusion we derive from this analysis is that NOEM models are still very far away from offering a satisfactory explanation for exchange rate dynamics. Our finding of an explanatory power of 10 percent is not out of line with results from other studies. Since the failure of the model in this respects is likely due to several factors, this will be an active research area for years to come.

\section{Conclusion}

This paper has developed and estimated a two-country NOEM model using a Bayesian approach. We provide estimates for various prior distributions and document the extent to which inference is robust and sensitive to the choice of priors. The model can be extended to an incomplete market setting that could be used to study current account dynamics. Although construction of a bilateral current account data set is not straightforward, the same procedure that we used in constructing the exchange rate series could be employed. Adding another data series requires the introduction of another disturbance. A likely candidate is a shock to the UIP relationship. Our benchmark estimates reject that specification in favor of a PPP shock, but the former 
may contain information that helps explain current account dynamics, as in Bergin (2004). Real exchange rate dynamics in our model depend exclusively on movements in relative prices of traded goods. However, movements in the prices of nontraded goods are an important component of real exchange rates (see Betts and Kehoe 2004). The model can be extended to include a nontraded sector that is also subject to nominal rigidities. It is our presumption that this would help improve the overall fit of the model and help explain exchange rate movements endogenously.

It is also plausible to assume that the host of puzzles in international finance cannot be explained satisfactorily by models with fully rational agents. Attempts to integrate deviations from this benchmark have been made by Duarte and Stockman (2001) and, albeit in a less structural framework, by Gourinchas and Tornell (2004). While we used a log-linear approximation of our two-country model, nonlinearities might play an important role in the understanding of exchange rate fluctuations. Fernández-Villaverde and Rubio-Ramírez (2002) have made significant progress toward algorithms that enable the likelihood-based estimation of DSGE models solved with nonlinear methods.

A final challenge for researchers is how to communicate the fruits of their labor to a wider public, in particular, policymakers. We argue that a Bayesian approach is supremely useful for this. Researchers can report to what extent information comes from the likelihood function and to what extent it derives from the prior. This leaves it up to the policymaker to decide what value to place on the information conveyed. Finally, implementation has become much easier and more transparent due to available software. We provide GAUSS programs, and the analysis in this paper can be conducted with the user-friendly DYNARE package.

\section{Appendix}

\subsection{Data Set}

Most of the U.S. data were extracted from the FRED 2 database maintained by the Federal Reserve Bank of St. Louis: http://research .stlouisfed.org/fred2/. The Euro area data stem from the database underlying the Area Wide Model (AWM) of the European Central Bank, which is described in detail in Fagan, Henry, and Mestre (2001). Exchange rate data are obtained from the International Financial Statistics 
(IFS) database maintained by the International Monetary Fund (IMF) http://ifs.apdi.net/imf/.

- U.S. output growth (quarter-to-quarter, percent) is based on the real GDP series GDPC96-FRED2. We construct a measure of U.S. working age population (ages 16-64) from the series PAN17-DRI and PAN19DRI provided by DRI-Global Insight http://www.globalinsight.com/. The observations from 1990-1999 are updated using intercensal estimates, and the observations from 2000 onward are updated based on postcensal estimates http://www.census.gov/popest/. Annual data are converted to quarterly frequency using a quadratic interpolation. Per capita output growth is defined as $100 *\left[\ln \left(G D P_{f} / P O P_{f}\right)-\right.$ $\left.\ln \left(G D P_{t-1} / P O P_{t-1}\right)\right]$.

- U.S. inflation (quarter-to-quarter, annualized, percent) is based on the Consumer Price Index for All Urban Consumers, CPIAUCSL-Fred2. The monthly series is converted into quarterly frequency by arithmetic averaging. Inflation is defined as $400 * \ln \left(C P I_{t} / C P I_{t-1}\right)$.

- The U.S. nominal interest rate (annualized, percent) is the effective Federal Funds Rate FEDFUNDS-Fred2. The monthly series is converted into quarterly frequency by arithmetic averaging.

- Euro area output growth (quarter-to-quarter, percent) is based on the real output series $Y E R-A W M$. A measure of the Euro area working age population (ages 15-64) is obtained from the AMECO database http:// europa.eu.int. The Euro area series is extended backward using growth rates calculated from the Euro area (including West Germany) series. Annual population data are converted to quarterly frequency using a quadratic interpolation. Per capita output growth is defined as $100 *\left[\ln \left(Y E R_{t} / P P_{t}\right)-\ln \left(Y E R_{t-1} / P O P_{t-1}\right)\right]$.

- Euro area inflation (quarter-to-quarter, annualized, percent) is based on the Harmonized Index of Consumer Prices, HICP-AWM, and is defined as $400 * \ln \left(\mathrm{HICP}_{t} / \mathrm{HICP}_{t-1}\right)$.

- The Euro area nominal interest rate (annualized, percent) is defined as the short-term nominal rate STN-AWM.

- For exchange rate depreciation (quarter-to-quarter, percent), starting in 1999, we use the official US\$-Euro exchange rate obtained from the IFS database. Prior to 1999, we construct a synthetic bilateral exchange rate series. We extract US\$-national currency unit exchange rates $E_{i, t}$ for the Euro area countries from the IFS database and define: 
$E_{t}=\prod_{i=1}^{n}\left(f_{i} E_{i, t}\right)^{w_{i}}$

The weights $w_{i}$ correspond to the real GDP weights underlying the construction of the AWM database. ${ }^{18}$ The $f_{i}$ 's are the fixed conversion rates between the national currency units and the Euro. Taking logs and differences yields:

$\Delta \ln E_{t}=\sum_{i=1}^{n} w_{i} \Delta \ln E_{i, t}$

Thus, prior to 1999 , the depreciation rate of the synthetic US\$-Euro exchange rate is the output-weighted average of the depreciation rates of the national currencies. The depreciation rate is multiplied by 100 to convert it to percentages.

- The import shares that are used to specify a prior for $\alpha$ are defined as IMP/(GDP - EXP + IM). We are using EXPGSC96-FRED2 and IMPGSC96-FRED2 for the United States and XTR-AWM and XTR$A W M$ for the Euro area to measure real exports and imports, respectively.

\subsection{Practical Implementation}

The results reported in this paper have been computed using GAUSS 6.0. The GAUSS programs and the data set are available from the authors at http://www.econ.upenn.edu/ schorf. The empirical analysis can also be implemented using the MATLAB-based DYNARE package that is available at http://www .cepremap.cnrs.fr/dynare/.

1. The matrices $\Gamma_{0}(\theta), \Gamma_{1}(\theta), \Gamma_{\epsilon}(\theta)$, and $\Gamma_{\eta}(\theta)$ in equation (5.34) can be derived from the linearized equations presented in Section 3.6. The solution algorithun described in Sims (2002) is used to compute the state transition equation [equation (5.35)].

2. Combine equation (5.35) with the measurement equation [equation (5.36)] to form a state space model for the observables $y_{t}$. The matrix $A(\theta)$ in equation (5.36) is composed of:

$A(\theta)=\left[\gamma, \pi^{(A)}, r^{(A)}+\pi^{(A)}+4 \gamma, \gamma, \pi^{(A)}, r^{(A)}+\pi^{(A)}+4 \gamma, 0\right]^{\prime}$

where $y_{t}$ stacks U.S. output growth, U.S. inflation, the U.S. nominal interest rate, Euro area output growth, Euro area inflation, the Euro area nominal interest rate, and the depreciation rate. The matrix $B$ 
selects and scales the relevant model variables to construct $y_{t}$. The growth adjusted steady-state real rate is related to the discount factor $\beta$ through $\beta=1 /\left(1+r^{(A)} / 400\right)$.

3. The likelihood function $\mathscr{L}(\theta \mid Y)$ is evaluated with the Kalman filter. To make the DSGE model estimation comparable to the VAR estimation, which conditions on the first four observations to initialize lags, we run the Kalman filter from 1983:I to 2002:IV but calculate the likelihood based only on the observations from 1984:I to 2002:IV. Since $\ln p\left(Y \mid Y_{0}\right)=\ln p\left(Y, Y_{0}\right)-\ln p\left(Y_{0}\right)$, this adjustment of the Kalman filter yields a conditional likelihood function for the DSGE model.

4. A numerical-optimization procedure is used to maximize:

$p(\theta \mid Y) \propto \mathscr{L}(\theta \mid Y) p(\theta)$

and find the posterior mode. The inverse Hessian is calculated at the posterior mode.

5. A total of 500,000 draws from $p(\theta \mid Y)$ are generated with a randomwalk Metropolis algorithm. The scaled inverse Hessian serves as a covariance matrix for the Gaussian proposal distribution used in the Metropolis-Hastings algorithm. The first 50,000 draws are discarded. The parameter draws $\theta$ are converted into impulse response functions and variance decompositions to generate the results reported in Section 6. Posterior moments are obtained by Monte-Carlo averaging. Marginal data densities are approximated with Geweke's (1999) modified harmonic-mean estimator. Further details of these computations are discussed in Schorfheide (2000).

\subsection{Marginal Data Density of VAR}

We use a modified version of the Minnesota prior (see Doan, Litterman, and Sims 1984) that is implemented based on dummy observations. In the main text, we report results based on a VAR(4) with seven endogenous variables. Subsequently, we present the choice of dummy observations in the context of a bivariate VAR(2):

$\left[\begin{array}{l}y_{1, t} \\ y_{2, t}\end{array}\right]=\left[\begin{array}{l}\alpha_{1} \\ \alpha_{2}\end{array}\right]+\left[\begin{array}{ll}\beta_{11} & \beta_{12} \\ \beta_{21} & \beta_{22}\end{array}\right]\left[\begin{array}{l}y_{1, t-1} \\ y_{2, t-1}\end{array}\right]+\left[\begin{array}{ll}\gamma_{11} & \gamma_{12} \\ \gamma_{21} & \gamma_{22}\end{array}\right]\left[\begin{array}{l}y_{1, t-2} \\ y_{2, t-2}\end{array}\right]+\left[\begin{array}{l}u_{1, t} \\ u_{2, t}\end{array}\right]$

Define $y_{t}=\left[y_{1, f}, y_{2, t}\right]^{\prime}, x_{t}=\left[1, y_{t-1}^{\prime}, y_{t-2}^{\prime}\right]^{\prime}$, and $u_{t}=\left[u_{1, t}, u_{2, t}\right]^{\prime}$ and:

$\Phi^{\prime}=\left[\begin{array}{lllll}\alpha_{1} & \beta_{11} & \beta_{12} & \gamma_{11} & \gamma_{12} \\ \alpha_{2} & \beta_{21} & \beta_{22} & \gamma_{21} & \gamma_{22}\end{array}\right]$ 
The VAR can be rewritten as $y_{t}^{\prime}=x_{t}^{\prime} \Phi+u_{t}^{\prime}, t=1, \ldots, T$, and $u_{t} \sim$ itd $\mathcal{N}\left(0, \Sigma_{u}\right)$. The dummy observations that generate the prior can be classified as follows (the generalization to larger VAR systems is straightforward):

- Dummy observations for the $\beta$ coefficients, reflecting the belief that $\beta_{11}$ and $\beta_{22}$ are equal to $l$, and $\beta_{12}$ and $\beta_{21}$ are equal to 0 on average:

$\left[\begin{array}{cc}\imath \tau s_{1} & 0 \\ 0 & \imath \tau \varsigma_{2}\end{array}\right]=\left[\begin{array}{ccccc}0 & \tau \varsigma_{1} & 0 & 0 & 0 \\ 0 & 0 & \tau \varsigma_{2} & 0 & 0\end{array}\right] \Phi+u^{\prime}$

- Dummy observations for the $\gamma$ coefficients, reflecting the belief that the $\gamma^{\prime}$ s are 0 on average:

$\left[\begin{array}{ll}0 & 0 \\ 0 & 0\end{array}\right]=\left[\begin{array}{ccccc}0 & 0 & 0 & \tau s_{1} 2^{d} & 0 \\ 0 & 0 & 0 & 0 & \tau \varsigma_{2} 2^{d}\end{array}\right] \Phi+u^{\prime}$

- Co-persistence prior dummy observations, reflecting the belief that when data on all $y^{\prime}$ s are stable at their initial levels, they tend to persist at that level:

$\left[\begin{array}{ll}\lambda \bar{y}_{1} & \lambda \bar{y}_{2}\end{array}\right]=\left[\begin{array}{lllll}\lambda & \lambda \bar{y}_{1} & \lambda \bar{y}_{2} & \lambda \bar{y}_{1} & \lambda \bar{y}_{2}\end{array}\right] \Phi+u^{\prime}$

- Own-persistence prior dummy observations, reflecting the belief that when $y_{i}$ has been stable at its initial level, it tends to persist at that level, regardless of the value of other variables:

$\left[\begin{array}{cc}\mu \bar{y}_{1} & 0 \\ 0 & \mu \bar{y}_{2}\end{array}\right]=\left[\begin{array}{ccccc}0 & \mu \bar{y}_{1} & 0 & \mu \bar{y}_{1} & 0 \\ 0 & 0 & \mu \bar{y}_{2} & 0 & \mu \bar{y}_{2}\end{array}\right] \Phi+u^{\prime}$

- Dummy observations for the covariance matrix:

$\left[\begin{array}{cc}s_{1} & 0 \\ 0 & s_{2}\end{array}\right]=\left[\begin{array}{lllll}0 & 0 & 0 & 0 & 0 \\ 0 & 0 & 0 & 0 & 0\end{array}\right] \Phi+u^{\prime}$

The $\bar{y}_{i}$ 's and $s_{i}$ 's are calculated as means and standard deviations of the values of $y_{t}$ that are used to initialize the lags of the VAR. The parameters $\tau, d, \lambda$, and $\mu$ are hyperparameters that control the weight on different characteristics of the prior distribution. We set $d=0.5$, $\lambda=5$, and $\mu=2$, and we vary $\tau$, which controls the overall tightness of the prior. The typical Minnesota prior shrinks the VAR parameter estimates toward univariate random walks, which can be achieved by setting $l=1$. However, since we are using growth rates as dependent variables (interest rates being an exception), we set $l=0$. 
Write the system in matrix notation $Y=X \Phi+U$, where $Y, X$, and $U$ have rows $y_{t}^{\prime}, x_{t}^{\prime}$, and $u_{t}^{\prime}$, respectively. We condition on the observations that are used to initialize the lags of the VAR. The $T^{*}$ dummy observations are collected into the matrices $Y^{*}$ and $X^{*}$. The likelihood function $p\left(\Upsilon^{*} \mid \Phi, \Sigma_{u}\right)$ for the dummy observations combined with the improper prior distribution $p\left(\Phi, \Sigma_{u}\right) \propto\left|\Sigma_{u}\right|^{-(n+1) / 2}$ induces a proper prior distribution for the VAR parameters. The marginal data density of the VAR can be written as:

$p\left(\Upsilon \mid \Upsilon^{*}\right)=\frac{\int p\left(\Upsilon, \Upsilon^{*} \mid \Phi, \Sigma_{u}\right) d \Phi d \Sigma_{u}}{\int p\left(\Upsilon^{*} \mid \Phi, \Sigma_{u}\right) d \Phi d \Sigma_{u}}$

where $p\left(Y, Y^{*} \mid \Phi, \Sigma_{u}\right)$ is the joint likelihood function for actual and dummy observations. The integrals on the right-hand side of equation (5.45) can be obtained by replacing $\tilde{Y}, \tilde{X}$, and $\tilde{T}$ in the subsequent formula by $\left[Y^{\prime}, Y^{* \prime}\right]^{\prime},\left[X^{\prime}, X^{* \prime}\right]^{\prime}, T+T^{*}$ and $Y^{*}, X^{*}, T^{*}$ respectively:

$$
\begin{aligned}
\int p\left(\tilde{Y} \mid \Phi, \Sigma_{\mu}\right) d \Phi d \Sigma_{u}= & \pi^{-(\tilde{T}-k) / 2}\left|\tilde{X}^{\prime} \tilde{X}\right|^{-n / 2}|S|^{-(\tilde{T}-k) / 2} \pi^{n(n-1) / 4} \\
& \times \prod_{i=1}^{n} \Gamma[(\tilde{T}-k+1-i) / 2]
\end{aligned}
$$

where $n$ is the dimension of $y_{t}, k$ is the dimension of $x_{t}$ and:

$\hat{\mathbf{\Phi}}=\left(\tilde{X}^{\prime} \tilde{X}\right)^{-1} \tilde{X}^{\prime} \tilde{Y} \quad S=(\tilde{Y}-\tilde{X} \hat{\mathbf{\Phi}})^{\prime}(\tilde{Y}-\tilde{X} \hat{\mathbf{\Phi}})$

The specification of the dummy observations and the computation of the margmal data densities is implemented with MATLAB programs written by Chris Sims.

\section{Endnotes}

Thomas Lubik wishes to dedicate this paper to the memory of his father. Part of this research was conducted while Schorfheide was visiting New York University, for whose hospitality he is grateful. We thank Mark Gertler, Michael Krause, Paolo Pesenti, Pau Rabanal, Ken Rogoff, Chris Sims, John Williams, and seminar participants at the European Central Bank, Georgetown University, Johns Hopkins University, the NBER Macroeconomics Annual Conference, UC Davis, and the Federal Reserve Bank of San Francisco for useful comments and discussions. Thanks also to Frank Smets and Raf Wouters for making the Euro area data set available. Sungbae An provided excellent research assistance. Schorfheide gratefully acknowledges financial support from the Alfred P. Sloan Foundation. The GAUSS programs that were used for the computations reported in the paper are available at http://www.econ.upenn.edu/ $\sim$ schorf. 
1. Naturally, there have been various early attempts to take the NOEM framework to the data. Schunitt-Grohe (1998) matches impulse response functions from a structural VAR to theoretical impulse responses derived from a model of the Canadian economy to study the transmission of business cycles. Ghironi (2000) uses GMM to estimate various firstorder conditions derived from a NOEM model. None of these earlier approaches assesses overall fit or estimates the model over the entire parameter space.

2. Other early contributions to the literature on Bayesian estimation of DSGE models are DeJong, Ingram, and Whiteman (2000); Fernández-Villaverde and Rubio-Ramírez (2004); Landon-Lane (1998); and Otrok (2001).

3. An excellent survey of that literature can be found in Lane (2001).

4. de Walque and Wouters (2004) recently reported some preliminary results from a large-scale two-country model fitted to U.S. and Euro data. Since Justiniano and Preston (2004) include a reduced-form rest-of-the-world sector in their SOE model, their specification shares similarities with a two-country framework.

5. See the discussion of the implications of market completeness in Corsetti and Pesenti (2001). Under incomplete asset markets, devices such as portfolio adjustment costs have to be introduced to render the model stationary. Schunitt-Grohé and Uribe (2003) show that the differences to the complete market benchmark are quantitatively negligible.

6. Our framework extends Monacelli (2005) to a large open economy setting. This form of endogenous pass-through has also been studied by Justiniano and Preston (2004) and Leigh and Lubik (2005).

7. We ignore household-specific indices for notational convenience.

8. Each domestic- and foreign-produced goods aggregate is composed of differentiated individual products with demand functions:

$C_{H, t}(i)=\left(\frac{P_{H, i}(i)}{P_{H, t}}\right)^{-\omega} C_{H, i} \quad$ and $\quad C_{F, t}(i)=\left(\frac{P_{F, i}(i)}{P_{F, t}}\right)^{-\omega} C_{F, i}$

and associated price indexes. We abstract from this level of disaggregation since it is immaterial to our aggregate model specification.

9. We assume that the government shares the preferences of the consumers so that its demand has the same functional form. Moreover, we also assume for simplicity that firms do not engage in local currency pricing. An extension of the model in this regard would be a promising research direction.

10. For a variable $x_{t}$, one can define $\eta_{t}^{x}=\tilde{x}_{t}-\mathbb{E}_{t-1}\left[\tilde{x}_{t}\right]$ and include $\mathbb{E}_{t}\left[\tilde{x}_{i+1}\right]$ in the vector $\mathrm{s}_{t}$ to represent the model developed in Section 3 [equation (5.34)].

11. In fact, Smets and Wouters (2003) used more shocks and variables to overcome some aspects of model misspecification.

12. Formally, likelihood-based estimators tend to converge to the $\tilde{\theta}$ that minimizes the Kullback-Leibler discrepancy between the approximating model and the data generating process (see, for instance, White 1982).

13. To ensure determinacy, we assume $\alpha>1$ in $\mathscr{M}_{1}$ and $\left|\alpha-\sqrt{\alpha^{2}-4 \phi \alpha}\right|<2$ and $\left|\alpha+\sqrt{\alpha^{2}-4 \phi \alpha}\right|>2$ in $\mathscr{H}_{2}$. 
14. This is well-known in Bayesian econometrics. See Poirier (1998) for a discussion. It has been exploited in Lubik and Schorfheide (2004) when they estimated DSGE models with indeterminacies.

15. Over the sample period from 1983:I to 2002:IV, the correlation between depreciation rates calculated from our synthetic US\$-Euro exchange rate and the published US\$-ecu depreciation rates is greater than 0.99 .

16. There are typically subtle differences in model specification that make a direct comparison of estimates difficult. For instance, Rabanal and Rubio-Ramírez $(2003,2005)$ use a stationary version of the New Keynesian benchmark model and work with output data that are deviations from a quadratic trend. Lubik and Schorfheide (2004) use HP. filtered output and transform the exogenous technology and government-spending processes into a pure shift of the Euler equation and a pure shift of the price-setting equations with correlated innovations. Schorfheide (2005) uses output growth data and nontransformed structural shocks.

17. This exchange rate disconnect puzzle has been emphasized by Rogoff (1996) as the main challenge for open economy macro models.

18. These weights are: $\mathrm{BE}=0.036 ; \mathrm{DE}=0.283 ; \mathrm{ES}=0.111 ; \mathrm{FR}=0.201 ; \mathrm{IE}=0.015$; $\mathrm{IT}=0.195 ; \mathrm{LU}=0.003 ; \mathrm{NL}=0.060 ; \mathrm{AT}=0.030 ; \mathrm{PT}=0.024 ; \mathrm{FI}=0.017 ; \mathrm{GR}=0.025$.

\section{References}

Adolfson, Malin, Stefan Laseén, Jesper Lindé, and Mattias Villani (2004). "Bayesian Estimation of an Open Economy DSGE Model with Incomplete Pass-Through," Sveriges Riksbank, manuscript.

Ahmed, Shaghil, Barry Ickes, Ping Wang, and Byung Sam Yoo (1993). "International Business Cycles," American Economic Review, 83:335-359.

Ambler, Steve, Ali Dib, and Nooman Rebei (2004). "Optimal Taylor Rules in an Estimated Model of a Small Open Economy," Bank of Canada, manuscript.

Angeloni, Ignazio, Luc Aucremanne, Michael Ehrmann, Jordi Galí, Andrew Levin, and Frank Smets (2004). "Inflation Persistence in the Euro Area: Preliminary Summary of Findings," European Central Bank, manuscript.

Bergin, Paul R. (2003). "Putting the 'New Open Economy Macroeconomics' to a Test," Journal of International Economics, 60:3-34.

Bergin, Paul R. (2004). "How Well Can the New Open Economy Macroeconomics Explain the Exchange Rate and the Current Account?" Journal of International Money and Finance, forthcoming.

Betts, Caroline, and Timothy Kehoe (2004). "U.S. Real Exchange Rate Fluctuations and Relative Price Fluctuations," Federal Reserve Bank of Minneapolis, staff report no. 334.

Beyer, Andreas, and Roger Farmer (2004). "On the Indeterminacy of New Keynesian Economics," ECB, working paper no. 323.

Bils, Mark, and Peter Klenow (2004). "Some Evidence on the Importance of Sticky Prices," Joumal of Political Economy, 112:947-985. 
Campa, Jose Manuel, and Linda Goldberg (2004). "Exchange Rate Pass-Through into Import Prices," Review of Economics and Statistics, forthcoming.

Chari, V. V., Patrick Kehoe, and Ellen McGrattan (2002). "Can Sticky Price Models Generate Volatile and Persistent Real Exchange Rates," Review of Economic Studies, 69:533563.

Christiano, Lawrence J., Martin Eichenbaum, and Charles Evans (2005). "Nominal Rigidities and the Dynamic Effects of a Shock to Monetary Policy," Journal of Political Economy, 113:1-45.

Clarida, Richard, and Jordi Galí (1994). "Sources of Real Exchange-Rate Fluctuations," Carnegie-Rochester Conference Series on Public Policy, 41:1-56.

Clarida, Richard, Jordi Galí, and Mark Gertler (1998). "Monetary Policy Rules in Practice: Some International Evidence," European Economic Review, 42:1033-1067.

Clanda, Richard, Jordi Galí, and Mark Gertler (1999). "The Science of Monetary Policy: A New Keynesian Perspective," Journal of Economic Literature, 37:1661-1707.

Corsetti, Giancarlo, and Paolo Pesenti (2001). "Welfare and Macroeconomic Interdependence," Quarterly Journal of Economics, 116:421-445.

DeJong, David, Beth Ingram, and Charles Whiteman (2000). "A Bayesian Approach to Dynamic Macroeconomics," Jourtal of Econometrics, 98:201-223.

Del Negro, Marco (2003). "Fear of Floating: A Structural Estimation of Monetary Policy in Mexico," Federal Reserve Bank of Atlanta, manuscript.

Del Negro, Marco, and Frank Schorfheide (2004). "Priors from General Equilibrium Models for VARs," International Economic Review, 45:643-673.

Del Negro, Marco, Frank Schorfheide, Frank Smets, and Raf Wouters (2004). "On the Fit and Forecasting Performance of New Keynesian Models," University of Pennsylvania, manuscript.

de Walque, Grégory, and Raf Wouters (2004). "An Open Economy DSGE Model Linking the Euro Area and the U.S. Economy," National Bank of Belgium, manuscript.

Dib, Ali (2003). "Monetary Policy in Estimated Models of Small Open and Closed Economies," Bank of Canada, working paper no. 2003-27.

Doan, Thomas, Robert Litterman, and Chnistoper Sims (1984). "Forecasting and Condiional Projections Using Realistic Pror Distributions," Econometric Reviews, 3:1-100.

Duarte, Margarida, and Alan C. Stockman (2001). "Rational Speculation and Exchange Rates," NBER working paper no. 8362.

Erceg, Christopher, Luca Guerneri, and Christopher Gust (2005). "Expansionary Fiscal Shocks and the Trade Deficit," Board of Governors of the Federal Reserve System, International Finance Discussion Papers no. 825.

Fagan, Gabriel, Jerome Henry, and Ricardo Mestre (2001). "An Area-Wide Model (AWM) for the Euro Area," European Central Bank (ECB), working paper no. 42.

Fernández-Villaverde, Jesús, and Juan Rubio-Ramírez (2002). "Estimating Nonlinear Dynamic Equilibrium Economies: A Likelihood Approach," University of Pennsylvania, manuscript. 
Femández-Villaverde, Jesús, and Juan Rubio-Ramírez (2004). "Comparing Dynamic Equilibrium Models to Data," Journal of Econometrics, 123:153-187.

Galí, Jordi, and Tommaso Monacelli (2005). "Monetary Policy and Exchange Rate Volatility in a Small Open Economy," Review of Economic Studies, 72:707-734.

Gali, Jordi, and Pau Rabanal (2004). "Technology Shocks and Aggregate Fluctuations: How Well Does the RBC Model Fit Postwar U.S. Data," NBER Macroeconomics Annual, 19:225-288.

Geweke, John (1999). "Using Simulation Methods for Bayesian Econometric Models: Inference, Development, and Communications," Economerric Reviews, 18:1-127.

Ghironi, Fabio (2000). "Towards a New Open Economy Macroeconometrics," Boston College working paper no. 469 .

Gourinchas, Pierre-Olivier, and Aaron Tomell (2004). "Exchange Rate Puzzles and Distorted Beliefs," Joumal of International Economics, 64:303-333.

Justiniano, Alejandro, and Bruce Preston (2004). "Small Open Economy DSGE ModelsSpecication, Estimation, and Model Fit," Columbia University, manuscript.

Kydland, Finn, and Edward Prescott (1982). "Time to Build and Aggregate Fluctuations," Econometrica, 50:1345-1370.

Kydland, Finn, and Edward Prescott (1996). "The Computational Experiment: An Econometric Tool," Journal of Economic Perspectives, 10:69-85.

Landon-Lane, John (1998). "Bayesian Comparison of Dynamic Macroeconomic Models," University of Minnesota, Ph.D. dissertation.

Lane, Philip (2001). "The New Open Macroeconomics: A Survey," Joumal of International Economics, 54:235-266.

Laxton, Douglas, and Paolo Pesenti (2003). "Monetary Policy Rules for Small, Open, Emerging Economies," Journal of Monefary Economics, 50:1109-1146.

Leeper, Eric, and Christoper Sims (1994). "Toward a Modem Macroeconomic Model Usable for Policy Analysis," NBER Macroeconomics Annual, 9:81-118.

Leigh, Daniel, and Thomas Lubik (2005). "Monetary Policy and Imperfect Pass-Through: A Tale of Two Countries," Johns Hopkins University, manuscript.

Lubik, Thomas, and Frank Schorfheide (2004). "Testing for Indeterminacy: An Application to U.S. Monetary Policy," American Economic Review, 94:190-217.

Lubik, Thomas, and Frank Schorfheide (2006). "Do Central Banks Respond to Exchange Rate Fluctuation-A Structural Investigation," Journal of Monetary Economics, forthcoming.

Monacelli, Tommaso (2005). "Monetary Policy in a Low Pass-Through Environment," Journal of Money, Credit, and Banking, forthcoming.

Obstfeld, Maurice, and Kenneth Rogoff (1995). "Exchange Rate Dynamics Redux," Journal of Political Economy, 103:624-660.

Otrok, Christopher (2001). "On Measuring the Welfare Cost of Business Cycles," Journal of Monetary Economics, 47:61-92. 
Poirier, Dale (1998). "Revising Beliefs in Nonidentified Models," Econometric Theory, 14:183-209.

Rabanal, Pau, and Juan Rubio-Ramirez (2003). "Comparing New Keynesian Models in the Euro Area: A Bayesian Approach," Federal Reserve Bank of Atlanta, working paper no. 2003-30.

Rabanal, Pau, and Juan Rubio-Ramirez (2005). "Comparing New Keynesian Models of the Business Cycle: A Bayesian Approach," revised version of Federal Reserve Bank of Atlanta, working paper no. 2001-22.

Robert, Christian (1994). The Bayesian Choice. New York: Springer-Verlag.

Rogoff, Kenneth (1996). "The Purchasing Power Parity Puzzle," Journal of Economic Literature, 34:647-668.

Rotemberg, Julio, and Michael Woodford (1997). "An Optimization-Based Econometric Framework for the Evaluation of Monetary Policy," NBER Macroeconomics Annual, 12:297-346.

Sargent, Thomas (1989). "Two Models of Measurements and the Investment Accelerator," Journal of Political Economy, 97(2):251-287.

Schmitt-Grohé, Stephanie (1998). "The International Transmission of Economic Fluctuations: Effects of U.S. Business Cycles on the Canadian Economy," Journal of International Economics, 44:257-287.

Schmitt-Grohé, Stephanie, and Martín Uribe (2003). "Closing Small Open Economy Models," Journal of International Economics, 61:163-185.

Schorfheide, Frank (2000). "Loss Function-Based Evaluation of DSGE Models," Journal of Applied Econometrics, 15:645-670.

Schorfheide, Frank (2005). "Learning and Monetary Policy Shifts," Review of Economic Dynamics, 8:392-419.

Sims, Christopher (1980). "Macroeconomics and Reality," Econometrica, 48:1-48.

Sims, Christopher (2002). "Solving Linear Rational Expectations Models," Computational Economics, 20:1-20.

Smets, Frank, and Raf Wouters (2002). "Openness, Imperfect Exchange Rate Passthrough, and Monetary Policy." Joumal of Monetary Economics, 49(5):947-981.

Smets, Frank, and Raf Wouters (2003). "An Estimated Stochastic Dynamic General Equilibrium Model for the Euro Area," Joumal of the European Economic Association, 1(5):11231175 .

Smets, Frank, and Raf Wouters (2004). "Comparing Shocks and Frictions in U.S. and Euro Area Business Cycles: A Bayesian DSGE Approach," National Bank of Belgium, working paper no. 61 .

White, Halbert (1982). "Maximum Likelihood Estimation of Misspecified Models," Econometrica, 50:1-25.

Woodford, Michael (2003). Interest and Prices. Princeton, N.J.: Princeton University Press. 


\section{Comment}

Paolo Pesenti, Federal Reserve Bank of New York, NBER, and CEPR

In their paper, Thomas Lubik and Frank Schorfheide introduce and estimate a midsize two-country model of monetary interdependence. The key building blocks of the model are rather well known, having been extensively investigated in the large (and growing) dynamic stochastic general equilibrium (DSGE) literature. The open-economy dimensions of the paper are perhaps less familiar, and it is precisely on those aspects that this comment is focused.

\section{A Bayesian Look at What?}

The "new open-economy macroeconomics" (NOEM) referred to in the title is more of a synthesis of disparate elements than a well-defined "school of thought" (the term was originally coined by Ken Rogoff to emphasize differences with respect to the "old" paradigm in international finance, as represented by the Mundell-Fleming-Dornbusch tradition). With important differences in style and emphasis, the NOEM is closely related to recent tendencies in monetary economics and represents the open-economy counterpart to popular research approaches whose labels range from neo-Wicksellian to new Keynesian, to new neoclassical. In this respect, the basic ingredients of NOEM models are imperfect competition in labor and/or product markets, nominal rigidities, and optimal price-setting behaviors leading to time-varying markups.

The NOEM also attempts to bridge the gap with the recent international trade literature, although the integration between the two research areas is, to say the least, far from complete. For instance, the macroeconomic analyses of openness and interdependence considered in NOEM models typically focus on the intensive margin of international trade (exports and imports of a given set of varieties), 
downplaying or ruling out tout-court its extensive margin (exports and imports of new varieties), even though the latter plays a key role in the new trade literature both at the theoretical and empirical level. While recent work is slowly pushing the research frontier in these respects, the bulk of NOEM contributions do not allow for endogenous entry of firms, the creation of new varieties of goods, or changes in the array of traded and nontraded good. The paper by Lubik and Schorfheide is no exception here.

While NOEM models come in different sizes and varieties, they usually tend to be skewed bimodally either toward the "bonsai" end of the complexity spectrum (simple qualitative models of predominantly theoretical interest), or toward the "Godzilla" opposite end (large-scale, multicountry DSGE models with a wealth of parametric features). Among the earliest and most influential examples of the first kind of models, Obstfeld and Rogoff's (1995) work has now reached the status and reputation of a modern classic. Models of the second type have found fertile ground among central banks and policy institutions, with the Global Economy Model developed at the International Monetary Fund (IMF) possibly representing the best-known application so far. ${ }^{1}$

The paper by Lubik and Schorfheide is particularly welcome because it represents a relatively rare type of contribution at a position equidistant between the two extreme poles of the complexity spectrum (let's call it the Totoro region ${ }^{2}$ ). In fact, the authors devote an entire section of the paper to the discussion of the finely balanced trade-offs between misspecification and identification issues arising in DSGE models. However, this need not mean that theoretical and empirical aspects (or, if one prefers, specification and estimation sides of the model) are given equal attention in the paper. In fact, the formal framework of the paper is a simple variant of the canonical NOEM model, and the theoretical setup turns out to be little more than a pretext for the application of state-of-the-art Bayesian estimation techniques.

In a nutshell, the paper considers a world economy equally split between two large trading partners, the United States and the Euro area (EU). The two countries are symmetric in terms of technology and tastes (although tastes are skewed toward local goods, and such home bias in preferences implies that purchasing power parity [PPP] would not hold even if the law of one price held for all goods). They differ, however, in two important respects, both related to the specification of the monetary economies: the mechanism of policy transmission (that is, the size and persistence of nominal rigidities) is different across 
countries, and the interest rate rules followed by the two monetary authorities put different weights on output and inflation gaps, presumably reflecting different strategies and policy objectives.

Complete markets are assumed to exist both at the national and international level. For each tradeable good, the law of one price applies at the border level; that is, the price paid by the importer and the price received by the producer are equalized when expressed in terms of the same currency. This implies complete pass-through of exchange rate movements onto import prices at the border level. However, there is imperfect exchange rate pass-through at the consumer level, reflecting the monopoly power of importers in the domestic retail market (we will return to this point shortly). Uncertainty is introduced in the model through a smorgasbord of shocks, including a nonstructural disturbance that is designed to measure exogenous deviations from PPP (see Section 5.1).

While the approach of the paper is "deliberately parsimonious in order to focus on robustness and identification instead of fit," one must acknowledge, of course, that this level of theoretical abstraction is not problem-free. In fact, several simplifying (and unrealistic) assumptions-that make sense only in the minimalist context of the bonsai NOEM models-are imported without much discussion in the work by Lubik and Schorfheide, raising the possibility of mild or severe misspecification.

Take, for instance, the assumption of complete markets and full international risk-sharing, according to which a set of contingent transfers guarantees that the real exchange rate moves in tandem with the ratio of marginal utilities of the representative households in the two countries [see equation (5.30)]. This assumption implies that, across countries, consumption should be higher where its price is lower. The problem is that this is not true at all in the data, as recognized by a long tradition of empirical work dating back to Backus and Smith (1993). Besides raising doubts about the ability of the model to fit the dynamic profile of the U.S.-European current account, the crucial question is how empirically reliable should we judge the results of a methodology that forces the correlation between the two key variables in the analysis-relative consumption and real exchange rate-to be high when in the data it appears to be very low, if not negative.

Some problems with the model are discussed in the text-such as the absence of a nontraded sector, which is acknowledged in the conclusion. Other problematic aspects are less obvious, such as the 
specification of exchange rate pass-through. Recall that price stickiness and low pass-through arise at the consumer level. There is no pricing to market or imperfect pass-through at the border level: the importer-currency price of imports moves one to one with the exchange rate, but the price paid by the consumer is less elastic to changes in exchange rates (the empirical evidence is that pass-through is indeed higher at the import level than at the consumer level, although it is still imperfect).

In the model, producers operate under conditions of monopolistic competition. When they sell in the domestic market, facing a downward-sloping demand for their specific varieties, they exploit their monopoly power by charging a markup over their marginal costs. Due to nominal rigidities, there is asymmetric adjustment, price dispersion among producers, and inflation dynamics in the aggregate. When the same producers sell their products to foreign importers, however, they do so at precisely the same price charged in the domestic market. In other words, they do not take into account the fact that the demand for their products abroad is a function of the consumer price set by the foreign importers. Since the latter is subject to nominal rigidities unrelated to those in the home market, the demand elasticities at home and abroad can be different. In this case, it is unlikely that the monopolistic producer/exporters find it optimal to give up their monopoly power and charge the same price both domestically and abroad.

Note that in a small open-economy model, this particular way of modeling lower pass-through at the consumer level rather than the border level would be perfectly valid because importers face an exogenously given price for their import goods. In the general-equilibrium framework of the model, however, the postulated absence of price discrimination seems logically inconsistent with the principle of profit maximization.

\section{Does Openness Make a Difference?}

The minimum common denominator of NOEM contributions (and NOEM's raison d'etre) is the investigation of policy transmission and the design of monetary rules among interdependent economies. To assess the relevance of the contribution by Lubik and Schorfheide in the context of the literature, it may prove useful to keep in mind a few key results in the NOEM tradition. Among those is the characterization of markup stabilization as a principle of optimal monetary policy. 
Broadly speaking, in a closed-economy multi-sector setting, the key principle underlying optimal monetary policies is the stabilization of some weighted average of markups in the product (and labor) markets, with higher weights assigned to the sectors in which price (wage) adjustment is most sluggish-a principle consistent with the notion of core inflation targeting. In an open-economy context, there is a tradeoff between stabilizing markups of local firms selling in the domestic market and markups of foreign exporters also selling in the country. The trade-off may depend on the degree of openness and the passthrough elasticity of consumer prices with respect to exchange rate fluctuations and other factors affecting changes in exporters' marginal costs.

For instance, if pass-through is very high, exchange rate fluctuations do not affect exporters' markups. In this case, optimal monetary policy stabilizes only domestic markups (that is, focuses only on domestic inflation). This policy is inward-looking, thus substantially similar to the optimal policy strategy in a closed economy because exchange rate movements make up for the lack of price flexibility in the import sector. This point has been stressed by Clarida, Gali, and Gertler (2001), among others. One may refer back to Friedman (1953) for early traces of the same basic idea. But if pass-through is low and if the exchange rate plays no expenditure-switching role, optimal monetary policy reacts to shocks worldwide and possibly dampens exchange rate fluctuations. ${ }^{3}$

This paper takes off from these considerations. In fact, its starting point is the Clarida, Galí, and Gertler model augmented by monopolistic importers who buy goods at the border and sell them to consumers, as seen above. The key question addressed in the paper is: are monetary policies in open economies significantly different from monetary policies in closed economies? To answer this question, the authors consider two specifications of the model, one in which the U.S. and EU countries are considered as two closed economies coexisting in autarky, and one in which the two countries engage in bilateral trade.

After estimating the model under the two specifications, the answer of the paper is a solomonic yes and no; depends. In the European case, moving from a closed- to an open-economy setting seems to make quite a difference. But in the U.S. case, not much differs whether or not the model accounts for the imports sector. ${ }^{4}$ As a result, openness makes monetary policies less asymmetric across countries. 
What happens is that the estimated degree of price stickiness in the EU market for domestic goods increases substantially when we move from the autarkic specification to the world-economy model. This result has important implications for EU monetary policy. When we allow for openness, the weight on inflation falls in the estimated interest rate rule, and concern with the output gap becomes predominant in policy design. ${ }^{5}$

Why so? The paper falls a bit short on economic intuition. In the context of the NOEM results above, one could suggest the following hypothesis. Suppose prices in one sector of the EU economy (say, domestic goods) are relatively more sticky, and prices in the other sector (say, imports) are relatively more flexible. If the model is brought to the data without accounting for sectoral differences, the estimated degree of nominal inertia relevant for policy decisions is some national average of the two sectors, prompting a relatively aggressive reaction to inflationary pressure because the costs of disinflation are perceived as low. But as soon as sectoral differences are taken into account, the degree of consumer price stickiness and inflation persistence in the domestic sector becomes more relevant, raising the sacrifice ratio faced by the EU authorities and prompting a more balanced policy response to inflationary pressure and the output gap.

But this interpretation raises as many questions as it answers. If the import sector exhibits more price flexibility than the domestic one, why is the estimated degree of import price stickiness in the EU higher than in the domestic sector? And why don't we observe similar results in the case of the United States? One could argue that pass-through is so low in the United States that it makes the estimated differences in the degrees of price stickiness across sectors negligible. But it is not clear whether this is the case: quite interesting-or puzzling-is that home and foreign output are found to be basically independent of the degree of exchange rate pass-through onto import prices, or more generally the degree of import price stickiness.

Of course, in light of the theoretical considerations above, one may suggest some caution in interpreting these pass-through estimates. And perhaps similar results would arise if one moved from a onesector to a multi-sector model of the EU economy, suggesting that openness and international considerations have little to do with asymmetries in monetary policies. At the end of the day, it is not clear how robust these results are. After all, they seem to disappear as soon as the estimation is based on demeaned data. 
In conclusion, the paper provides food for thought. The open question, needless to say, is, To what extent does model misspecification affect the validity of these results? Because the bilateral exchange rate is the only open-economy variable used in the analysis, it is not clear how much the model is able to tell us about the international transmission mechanism. And the fact that ad-hoc PPP shocks explain 93 percent of the variability of the depreciation rate obviously begs for some drastic improvements in the theoretical specification and a fuller validation of the model.

Fortunately, we won't have to wait too long for corroborations or refutations of these results. It is an easy prediction that, accounting for the user-friendliness of the DYNARE package and its rapid spread among Bayesian buffs, there will be a bubble-like trend in the number of papers experimenting with the Metropolis-Hastings algorithin in the attempt to re-estimate the Lubik-Schorfheide model or some $\mathrm{N}$ country variant thereof.

\section{Endnotes}

1. Laxton and Pesenti (2003) and Faruqee et al. (2005) document different stages of progress in the development of the Global Economy Model.

2. Tonari no Totoro (My neighbor Totoro) is a dassic animation film by Hayao Miyazaki.

3. See Devereux and Engel (2003) and Corsetti and Pesenti (2005) for a synthesis of this argument.

4. The estimates in the conference version of the model, based on a few different assumptions, led to opposite conclusions, as the authors mention in Section 6.1.3.

5. Exchange rate movements do not play any autonomous role in policy design besides their impact on the outlook for prices and output.

\section{References}

Backus, D. K., and G. W. Smith (1993). "Consumption and Real Exchange Rates in Dynamic Economies with Non-traded Goods," Joumal of International Economics, 35(34):297-316.

Clarida, R., J. Galí, and M. Gertler (2001). "Optimal Monetary Policy in Open Us. Closed Economies: An Integrated Approach," American Economic Reviewo Papers and Proceedings, 91(2):248-252.

Corsetti, G. and P. Pesenti (2005). "International Dimensions of Optimal Monetary Policy," Journal of Monetary Economics, 52(2):281-305.

Devereux, M. B., and C. Engel (2003). "Monetary Policy in the Open Economy Revisited: Price Setting and Exchange Rate Flexibility," Review of Economic Studies, 70:765-783. 
Faruqee, H., D. Laxton, D. Muir, and P. Pesenti (2005). "Smooth Landing or Crash? Model-Based Scenarios of Global Current Account Rebalancing," in R. Clarida (ed.), G7 Current Account Imbalances: Sustainability and Adjustment. Chicago, Ill.: University of Chicago Press, forthcoming.

Friedman, M. (1953). "The Case for Flexible Exchange Rates," in Essays in Positive Economics. Chicago, Ill.: University of Chicago Press, 157-203.

Laxton, D., and P. Pesenti (2003). "Monetary Rules for Small, Open, Emerging Economies," Journal of Monetary Economics, 50(5):1109-1146.

Obstfeld, M., and K. Rogoff (1995). "Exchange Rate Dynamics Redux," Journal of Political Economy, 103:624-660. 


\section{Comment}

Christopher A. Sims, Princeton University

\section{There's Not Much to Criticize Here}

My comments on the meeting draft of this paper focused mainly on the absence in that draft of serious attention to model fit. None of my criticisms of the paper on that account apply to this revised version of the paper. The paper now includes a nice discussion of Bayesian model comparison and provides us with comparisons of this structural model's fit to that of nonstructural Bayesian vector autoregressions (VARs). I fully agree with the paper's arguments in favor of likelihood-based methods for fitting and comparing models, as opposed to single-equation or impulse-response-matching approaches that have been more common in the literature.

The model itself is a pioneering effort at making behavioral sense of a two-country data set. It invokes a number of restrictions that may have limited its ability to fit the data or that limit its usefulness as a policy-projection tool. But some such restrictions are necessary, and it is hard to argue that this model is a bad start. My main substantive criticism of the model, that its assumption of no net asset accumulation makes it incapable of analyzing the current account, has all along been acknowledged in the paper's conclusion, in the form of an agenda for future research. My comments will therefore focus on some less central, though still I hope interesting, aspects of the paper.

\section{Model Fit: The Glass Is Half Full}

The $\log$ marginal data densities displayed in table 5.6, interpreted mechanically, imply overwhelming odds in favor of a VAR specification. The best VAR fit, with $\tau=5$, has a marginal data density that is higher by 9.32 in natural log units than its nearest competitor, the diffuse prior 
II dynamic stochastic general equilibrium (DSGE). This implies odds of about 10,000 to 1 in favor of the VAR. But note that the VAR fit varies sharply with the prior tightness parameter. This by itself would not weaken the evidence against the DSGE. If prior probability were spread equally across the four VAR models in the table and the diffuse prior II DSGE, the posterior odds against the DSGE would still be nearly the same. But the fact that posterior odds vary so strongly with the prior tightness suggests that analysis of further plausible variations in the DSGE prior and model structure might bring its fit into line with that of the VARs.

Of course, diffuse prior II allows the posterior estimate of $\alpha$, the import share, to move firmly into an area that makes no sense within the model's current behavioral interpretation, so the fact that it has by far the best fit among the DSGE specifications is in itself a criticism of the model specification. Therefore, matching the VAR fit more closely probably requires changing not only the prior but some aspects of the model's specification. Nonetheless, even though the model is clearly not yet ready for use in forecasting and policy projections, its performance is encouraging.

\section{Could the Model Comparison Methods Be More Refined?}

The paper points the reader to Schorfheide's loss-function-based framework and to the Del Negro-Schorfheide DSGE-based priors as a source for a "more refined" comparison of VARs and DSGEs. Here I disagree. Both these other approaches cited by the paper can produce interesting analyses, but neither provides a useful comparison of fit with VARs.

Schorfheide's loss-function-based theory assumes the availability of a loss function relevant to decision-making. It also assumes that expected losses can be assessed for all models being compared. The loss function plays an important role, distinct from likelihood, only when all the models being compared are dominated in fit by another model (the reference model) that is, for some reason, itself unusable but nonetheless can be used to evaluate expected loss for the other models. Since DSGEs are structural models that can be used to project the effects of policy, while unstructured VARs cannot be so used, this setup seems to fit the situation where DSGEs are compared to VARs. But nonstructural VARs cannot be used-precisely because they are not structural-to evaluate the expected losses from using badly fitting 
structural models. The Schorfheide framework can be artificially applied by assuming that the loss function is moment-matching, as if we cared directly about the accuracy of a model's predictions of certain moments in the data. But we do not in fact care about this, and if we did, there is no reason that reduced form VARs could not be used directly to match moments. To pretend that we should use a better-fitting VAR to evaluate the moment-matching ability of DSGEs, as if VARs are inconvenient to use in predicting moments, and as if moment-matching mattered for policy purposes (instead of being a crude shortcut in estimation), is no more than a classroom exercise.

The Schorfheide framework is worth studying because it provides insight into the pitfalls of using likelihood-based measures of fit on a collection of models, none of which fit well. It also may eventually be directly useful, for example, in a central bank that has a large, nonlinear DSGE model that fits well but is unwieldy for providing quick real-time projections of the effects of policy actions. Such a bank might want smaller, or limearized, structural models for making rapid projections, and Schorfheide's setup explains exactly how to choose among such handy, but clearly somewhat inaccurate, simple models using the large nonlinear model as a reference.

The Del Negro-Schorfheide setup generates a prior for a VAR from a DSGE and treats the tightness of the prior as a hyperparameter. When the marginal data density is high with the prior very tight, this suggests the DSGE model is not bad. This is not a comparison of the DSGE as a model for the data with the VAR as a model for the data, however. Such a comparison requires comparing a VAR with a prior to the DSGE with a prior. The type of comparison in this paper's table 5.6 is between, on the one hand, a (VAR) model and prior that treats variables symmetrically, using no knowledge of what the variables are, much less any economic theory, and on the other hand, a (DSGE) model and prior based on substantive considerations. This is therefore a test of the economic theory embodied in the DSGE and the substantive prior, versus simple smoothness and persistence priors with no economic content. The Del Negro-Schorfheide framework provides no such test. Since the VAR will need some prior, the framework will place some weight, maybe a lot of weight, on the DSGE prior, but we have no way of determining whether a good fit with a tight prior is coming from the DSGE simply generating smoothness and persistence or instead from the substantive economic content of the DSGE. 
This is not to say that we shouldn't aim for a more refined comparison of models than that in table 5.6. But the more refined comparison will require improving the DSGE at least, so that we have a few versions of it that are closer to each other and to the VARs in fit. If we were considering using the models for policy projections, it might also be useful to add a structural VAR to the list so that we could see to what extent differences in fit correspond to important differences in policy implications between more and less tightly restricted models. A similar result might be attained by adding a more richly parameterized version of the DSGE model to the list.

In other words, what is "unrefined" about the model comparisons in the paper is that the list of models is too lacking in serious competitors as probability models for the joint time series behavior of the data. Changing methods of model comparison will not fix this; only changing the list of models will.

\section{Purchasing Power Parity (PPP) Shocks}

The paper finds, as others have found before, that a representative agent, rational expectations structural model cannot explain much of the observed fluctuations in the exchange rate. This result emerges as a large variance for an ad hoc PPP shock in the exchange rate equation. Because this shock is both uninterpreted and statistically important, it creates a barrier to the use of the model for policy purposes. The model is absorbing some of the observed cross-variable dynamics into this uninterpreted error, and we must be uneasy about holding this shock constant as we consider policy experiments in the model.

It is disappointing that the paper leaves out of figure 5.2 the responses to the PPP shock. We know from table 5.7 that the responses would be large in the exchange rate column of figure 5.2, but our degree of concern about the large PPP shock could be affected by whether it feeds back in to other variables in the model. If there were little such feedback, it would be plausible to interpret the PPP shock as foreignexchange-market noise, unrelated to fundamentals. If there is strong feedback into other variables, this would raise more serious questions about the model's structure and might also give us insight into what type of extension of the model might bring this variation back in to the structure.

The agenda for future research based on this type of model should put high priority on adding model elements that could make devia- 
tions from uncovered interest parity (UIP) interpretable. There is some evidence that trading strategies that attempt to exploit deviations from UIP generate very high risk-return ratios (LeBaron 1998), which might serve as leverage for a theory based on market microstructure frictions. There is also evidence that foreign exchange risk premiums behave systematically and can be modeled (Brennan and Xia 2003), albeit not without considering higher than first-order moments.

\section{Conclusion}

I hope it is clear that, although my comments question some claims and choices the authors make in the paper, my overall assessment is that this paper is a big, well-executed step in the right direction for international macro-modeling.

\section{References}

Brennan, Michael J., and Yihong Xia (2003). "International Capital Markets and Foreign Exchange Risk," University of Pennsylvania, discussion paper.

LeBaron, B. (1998). "A Dynamic Trading Strategy Approach to Deviations from Uncovered Interest Parity," Brandeis University, discussion paper. 



\section{Discussion}

Comments focused on modeling choice, Bayesian techniques, and interpretation of the results.

Andrew Levin was surprised the authors chose to apply their model to the United States and Europe. To Levin, a more reasonable starting point for Bayesian estimation of new open-economy macroeconomic models is the classic case of a small open economy, or if the goal is to explore the interactions between two economies, Levin suggested starting with country pairs that do a substantial amount of trade with each other, such as the United States and Canada, or the Euro area and the United Kingdom. By contrast, the United States and the Euro area represent two economies that are relatively closed [trade is only about 10 percent of gross domestic product (GDP), only 10 percent of their trade is with each other, U.S. exports to the Euro area account for only 1 percent of U.S. GDP], and therefore it takes very large shocks to the Euro area before they show up in direct standard trade linkages. Levin was also concerned about a model that assumes a single monetary policy in each economy being fit to European data from the 1970s and 1980s.

In terms of Bayesian techniques, Ken Rogoff was curious about the authors' claim that Bayesian papers are easier to communicate to policymakers. Schorfheide acknowledged the challenge of communicating what exactly is learned from the data and how the prior distributions affect the conclusions that are ultimately reached. But he maintained that one can nicely capture the effects of uncertainty on the decision, and therefore the researcher can incorporate uncertainty into the decision-making process.

Chris Sims also was not so sure that it is easier to communicate Bayesian results. But he agreed with Schorfheide that Bayesian methodsin principle-allow one to combine the policymaker's subjective information with the model. According to Sims, the formal econometrics 
associated with previous styles of estimation is impossible to bring into policy discussions because it does not allow the researcher to integrate the subjective uncertainty that policymakers have.

Michael Woodford and Mark Gertler commented on the interpretation of the results. Michael Woodford wanted more intuition about the key empirical result of the paper: that the estimated frequency of price changes in the United States increases dramatically when you move from a closed-economy to an open-economy model. He wondered whether different measures of inflation or marginal cost were driving the result. He also wanted to know whether the model with more frequent price changes fits better in the open-economy version than in the closed-economy version, or whether the sticky model fits worse in the open-economy version than in the closed-economy version.

Regarding exchange rates, Mark Gertler wondered-in light of the research by Meese and Rogoff-whether these structural models can come close to a vector autoregression (VAR) in explaining exchange rate dynamics. If they cannot, he proposed that the model be segmented in some way so that the authors could look at the performance of quantities in the model (e.g., output, inflation), while recognizing that they are going to be way off on exchange rates.

Schorfheide responded that the additional shock $\varepsilon_{E}$ creates this exchange rate disconnect. Even with this shock, the authors could explain 20 percent of the variation in exchange rate differentials. However, when Lubik and Schorfheide forced this shock always to be 0, exchange rate fluctuations had to be explained by the other structural shocks in the model, giving technology shocks unreasonably high volatility. Thus, the authors concluded that this shock was necessary to control the contamination picked up by forcing the model to fit exchange rates. 